\title{
Seismic vulnerability and risk assessment of Kolkata City, India
}

\author{
S. K. Nath, M. D. Adhikari, N. Devaraj, and S. K. Maiti \\ Department of Geology and Geophysics, Indian Institute of Technology Kharagpur, 721302, West Bengal, India \\ Correspondence to: S. K. Nath (nath@gg.iitkgp.ernet.in)
}

Received: 10 December 2013 - Published in Nat. Hazards Earth Syst. Sci. Discuss.: 30 April 2014

Revised: 2 December 2014 - Accepted: 4 May 2015 - Published: 2 June 2015

\begin{abstract}
The city of Kolkata is one of the most urbanized and densely populated regions in the world and a major industrial and commercial hub of the eastern and northeastern region of India. In order to classify the seismic risk zones of Kolkata we used seismic hazard exposures on the vulnerability components, namely land use/land cover, population density, building typology, age and height. We microzoned seismic hazard of the city by integrating seismological, geological and geotechnical themes in GIS, which in turn are integrated with the vulnerability components in a logic-tree framework for the estimation of both the socioeconomic and structural risk of the city. In both the risk maps, three broad zones have been demarcated as "severe", "high" and "moderate". There had also been a risk-free zone in the city that is termed as "low". The damage distribution in the city due to the 1934 Bihar-Nepal earthquake of $M_{\mathrm{w}}=8.1$ matches satisfactorily well with the demarcated risk regime. The design horizontal seismic coefficients for the city have been worked out for all the fundamental periods that indicate suitability for "A", "B" and "C" type of structures. The cumulative damage probabilities in terms of "none", "slight", "moderate", "extensive" and "complete" have also been assessed for the predominantly four model building types viz. RM2L, RM2M, URML and URMM for each seismic structural risk zone in the city. Both the seismic hazard and risk maps are expected to play vital roles in the earthquake-inflicted disaster mitigation and management of the city of Kolkata.
\end{abstract}

\section{Introduction}

Earthquakes are a major menace to mankind, killing thousands of people every year in different parts of the globe. According to an estimate from National Geophysical Data Center (http://www.ngdc.noaa.gov), earthquakes during the last 100 years accounted for more than 1.9 million deaths. An estimated average of 17000 persons were killed every year. Seismic vulnerability in India is well evidenced by numerous past earthquake-related calamities viz. 1993 Killary earthquake of $M_{\mathrm{w}}=6.2,1997$ Jabalpur earthquake of $M_{\mathrm{w}}=5.8,1999$ Chamoli earthquake of $M_{\mathrm{w}}=6.8,2001$ Bhuj earthquake of $M_{\mathrm{w}}=7.7,2005$ Kashmir earthquake of $M_{\mathrm{w}}=7.6$ and 2011 Sikkim earthquake of $M_{\mathrm{w}}=6.9$. The 2001 Gujarat earthquake inflicted a total economic loss of about USD 4600 million approximately. The memory of the tsunami-genic 2004 Sumatra earthquake of $M_{\mathrm{w}}=9.1$ that wiped out more than 227000 lives is still very fresh. According to the Vulnerability Atlas of India published by the Building Materials and Technology Promotion Council, more than $59 \%$ of the total land cover of the country is susceptible to seismic hazard (BMTPC, 1997). Additionally, unplanned urbanization is expanding rapidly across the country to accommodate the burgeoning population. The fatalities in the urban agglomerations due to future great Himalayan earthquakes have been predicted to be around 150000 and 200000 (e.g., Wyss, 2005; Bilham et al., 2001). Dunbar et al. (2003) put the maximum expected earthquake loss in the country to be about USD 350-650 million for the next 50 years at $10 \%$ probability of exceedance.

The Kolkata metropolitan city is one of the most densely populated regions in the world and as a major business and industrial hub of east and northeast India it supports vital industrial and transportation infrastructures. The metropolitan city is placed at the margin of seismic zones III and IV as per the seismic zoning map of India (BIS, 2002). Sitting on a sedimentary basin of $7.5 \mathrm{~km}$ thickness above the crystalline basement it is highly vulnerable to earthquake disasters. The city was affected by near and far sources like the Bihar-Nepal seismic zone in the Central Seismic Gap, Assam Seismic Gap, Shillong Plateau, Andaman-Nicobar seis- 
mic province, Bengal Basin and the NE Himalayan extent (Nath et al., 2014). It is, therefore, apparent that earthquake catastrophes may happen anytime in the near future unless preventive measures are urgently taken towards disaster mitigation and management. Thus the vulnerability analysis of the city of Kolkata as undertaken in the present study involves multi-criteria risk evaluation through thematic integration of contributing vulnerability components viz. demography, land use/land cover (LULC), building typology, building age and building height.

The number of fatalities due to an earthquake is associated with the vulnerability of local buildings, population density and the intensity of ground shaking. Vulnerability exposure refers to all man-made facilities, namely the residential, commercial and industrial buildings, schools, hospitals, roads, bridges, pipelines, power plants and communication network, where an eventual seismic risk is predicted when exposed to seismic hazard. The seismic hazard is generally assumed to be stable over a long geological time while the typical vulnerability (and, therefore, the risk) to the hazard changes (McGuire, 2004). The risk is assessed as a convolution function of the hazard and the vulnerability, i.e., risk $=$ hazard $\cdot$ vulnerability. For the safety and sustainability of urban regions, it is, therefore, imperative to implement long-range urban planning and risk assessment mechanisms that rely heavily on accurate and multidisciplinary urban modeling. Therefore, the decisions to mitigate seismic risk require a logical but robust approach as given in HAZUS (1999) and RADIUS (2000) for evaluating the effects of future earthquakes on both people and infrastructure. In the present investigation we propose an alternative approach based on information extracted from satellite imagery, Google Earth and rapid visual screening for a broader estimation of socioeconomic and structural vulnerability of the city of Kolkata and the seismic risk thereof. The protocol consists firstly of seismic hazard microzonation involving the division of a region into subregions considering different hazard themes: (i) peak ground acceleration (PGA) at the surface, (ii) liquefaction potential index (LPI), (iii) NEHRP soil site class (SC), (iv) sediment class (SEC), (v) geomorphology (GM) and (vi) ground water table integrated on a hierarchical framework with the assignment of appropriate weights to each theme and associated ranks to the feature in each theme. Each hazard theme and the probabilistic seismic hazard assessment at both the rock level and surface consistency have been described in details in Nath et al. (2014). Secondly, the development of socioeconomic and structural seismic vulnerability exposures population density, building typology, building height, land use/land cover, building age, etc. using remote sensing, and GIS (Geographical Information System) comprises an integral component which is used to develop socioeconomic and structural seismic risk themes as vector layers in GIS through integration of seismic hazard with socioeconomic and structural vulnerability elements. An attempt thereupon is made to characterize the damage po- tential of prevalent building typologies viz. RM2L, RM2M, URML and URMM in the city of Kolkata. The open-source software package SELENA (Molina et al., 2010) has been used for the assessment of discrete damage probability considering different sets of building vulnerability curves in terms of its capacity and the associated fragility.

The spatial distribution of different vulnerability and risk entities is generated on a GIS platform and subsequently integrated through analytical hierarchal process (AHP) (Saaty, 1980). The ultimate goal of both the seismic hazard and seismic risk analysis is to develop the elements that can be used towards urban seismic safety. Thus, the study of seismic hazard and microzonation of the cities and urban centers enable us to characterize potential seismic vulnerability/risk, which needs to be taken into account while designing new settlement and lifeline facilities or retrofitting the existing ones. The risk appraisals, aimed at promoting reasonable hazard mitigation regulations, are generally based on vulnerability aspects such as socioeconomic aspects of land use and demographic distribution and the structural aspects of building typology.

\section{The city of Kolkata}

The Kolkata metropolis, the second largest urban agglomeration in India, bounded by latitudes of $22^{\circ} 27^{\prime}-22^{\circ} 40^{\prime} \mathrm{N}$ and longitudes of $88^{\circ} 18^{\prime}-88^{\circ} 28^{\prime} \mathrm{E}$, has developed primarily along the eastern bank of the River Hooghly about $150 \mathrm{~km}$ north of the Bay of Bengal, right over the Ganges delta. The population of Kolkata was 1.5 million in 1901, 11 million in 1991 and a phenomenal 14 million in 2011 according to the census report. Due to enormous population pressure it has encroached into the back swamp and marshy land to the east, filling up extensive areas, especially in the Salt Lake and Rajarhat regions, in an unplanned manner. More than $80 \%$ of the city has built-up areas with high-rise residential buildings, congested business districts, hospitals and schools, etc. (Nandy, 2007), some of which are very old and in dilapidated condition with unplanned construction adhering to non-seismic safety standards. Demography in some parts of the city exhibits population density above $100000 \mathrm{~km}^{-2}$. Figure 1 depicts the study region, which is urban Kolkata with typical urban attributions.

Kolkata is situated in the Bengal Basin, a huge pericratonic Tertiary basin with fluviomarine sediments of enormous thickness (Dasgupta et al., 2000). The Bengal Basin can be divided into three structural units: the westernmost shelf or platform, the central hinge or shelf/slope break and deep basinal part in the east and southeast that presently open in the Bay of Bengal (Alam et al., 2003; Das and Chattopadhyay, 2010). Kolkata is located over the western part of the hinge zone across which sediment thickness and facies significantly varies from shelf area in the west to the deep basinal part in the east. The most prominent tec- 

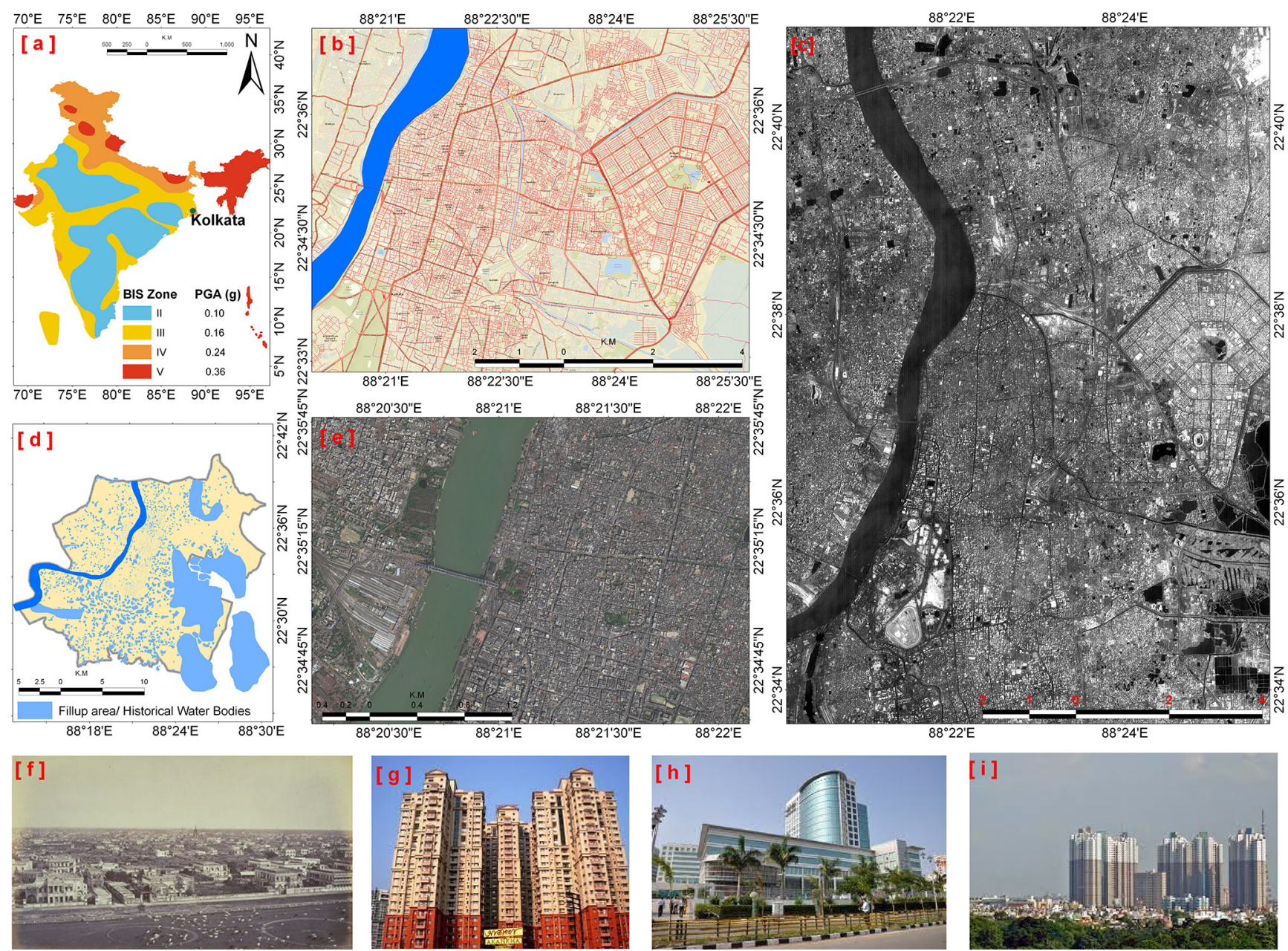

Figure 1. Urban Kolkata, the study region of the present investigation: (a) seismic zonation of India (BIS, 2002); (b) road network of the central part of the city; (c) the dense urban settlement of central Kolkata and Salt Lake regionas depicted in Cartosat-1 DEM (2011); (d) fill-up area/historical water bodies captured from Landsat MSS (1973) and the available historical maps (Rumsey, 1800, 1958, http: //www.davidrumsey.com); (e) GEO-eye (http://www.esri.com/data/basemaps) image of central Kolkata; and (f-i) representative old structure, skyscraper, steel structure, multi-storied structures of the city (see electronic supplement for a higher resolution version of this diagram).

tonic feature in the Bengal Basin is the NE-SW trending Eocene Hinge Zone (EHZ), also known as the CalcuttaMymensingh Hinge Zone. The EHZ is $25 \mathrm{~km}$ wide, extending to a depth of about $4.5 \mathrm{~km}$ below Kolkata. The hinge zone and the deep basin are overlain by thick alluvium to a maximum depth of about $7.5 \mathrm{~km}$. The tectonic grains of the Main Boundary Thrust, Main Central Thrust, Main Frontal Thrust, Dhubri Fault, Dauki Fault, Oldham Fault, Garhmoyna-Khandaghosh Fault, Jangipur-Gaibandha Fault, Pingla Fault, Debagram-Bogra Fault, Rajmahal Fault, Malda-Kishanganj Fault, Sainthia-Bahmani Fault, Purulia Shear Zone, Tista Lineament and Purulia Lineament largely influence the seismicity of the region. Besides its nearby sources, Kolkata is affected by far sources like Bihar-Nepal seismic zone in the Central Seismic Gap, Assam Seismic Gap, Shillong Plateau, Andaman-Nicobar seismic province and the NE Himalayan extent (Nath et al., 2014).
The city has been rocked time and again by both nearand far-field earthquakes of moderate to large magnitudes. Among the far-source earthquakes felt in Kolkata are the 1897 Shillong earthquake of $M_{\mathrm{W}}=8.1,1918$ Srimangal earthquake of $M_{\mathrm{w}}=7.6,1930$ Dhubri earthquake of $M_{\mathrm{w}}=7.1,1934$ Bihar-Nepal earthquake of $M_{\mathrm{w}}=8.1,1950$ Assam earthquake of $M_{\mathrm{w}}=8.7$ and 2011 Sikkim earthquake of $M_{\mathrm{w}}=6.9$. The Bihar-Nepal earthquake of $M_{\mathrm{w}}=8.1$ induced Modified Mercalli (MM) intensity of the order of VIVII in Kolkata (GSI, 1939) and caused considerable damage to life and property. The two near-source earthquakes reported in Kolkata are the 1906 Kolkata earthquake with MM intensity V-VI (Middlemiss, 1908) and the 1964 Sagar Island earthquake of $M_{\mathrm{w}}=5.4$ with damage intensity of MM VI-VII surrounding the city (Nath et al., 2010). However, the maximum intensity reported in Kolkata is MM VII, generated from both the near-source earthquake of 1964 and the 
distant earthquake of 1934, making the city highly vulnerable to seismic threat (Nath et al., 2014).

\section{Vulnerability exposures and thematic data layer preparation}

Unplanned urbanization defying building codes is continuously increasing the earthquake vulnerability of Kolkata, necessitating systematic assessment of seismic vulnerability by identifying those factors contributing to seismic risk in terms of socioeconomic and structural aspects. To understand the vulnerability of the built-up environment and infrastructure, a spatial/non-spatial database of building typology, building height, building age, land use/ and cover, population density and lifeline utilities has been created. These earthquake risk elements have been studied for different vulnerability levels in the seismic hazard microzonation perspective. Vulnerability index of various factors is calculated by defining an ordinal scale; overall vulnerability index maps of the study region have been prepared representing both the socioeconomic and structural entities. Figure 2 presents a framework for seismic vulnerability and risk assessment of the city of Kolkata.

The most common way of representing the confidence level in the assessment of remote sensing data is by computing an error matrix (Congalton, 1991). We derive error matrices for both the structural and socioeconomic vulnerability exposures for comparisons. It is based on the widely used accuracy assessment technique of statistical correlations between two map data sets - one categorized from the rapid visual screening (RVS) which we term as the "reference" and the other derived exclusively from remote sensing data which is termed as "classified" (Story and Congalton, 1986; Jensen, 1996). The correlation indicators used in the present analysis include "overall accuracy", i.e., the percentage of matched data between the "reference" and the "classified" maps; "user's accuracy", i.e., the percentage of matched data in the "classified" map; "producer's accuracy", i.e., the percentage of matched data in the "reference" map; and the kappa value defining a measure of the differences between the "reference" and the chance agreement between both the maps (Jensen, 1996; Congalton and Mead, 1983). The kappa value is expressed as (Bishop et al., 1975)

$k=\frac{N \sum_{i=1}^{r} X_{i i}-\sum_{i=1}^{r}\left(X_{i+} X_{+i}\right)}{N^{2}-\sum_{i=1}^{r}\left(X_{i+} X_{+i}\right)}$,

where $N$ is the total number of sites in the matrix, $r$ is the number of rows in the matrix, $X_{i i}$ is the number in row $i$ and column $i, X_{i+}$ is the total for row $i$ and $X_{+i}$ is the total for column $i$. The kappa statistics $>0.80$ suggests "strong" agreement, a value within a range of $0.60-0.80$ suggests "good" agreement and the chance of agreement is remote

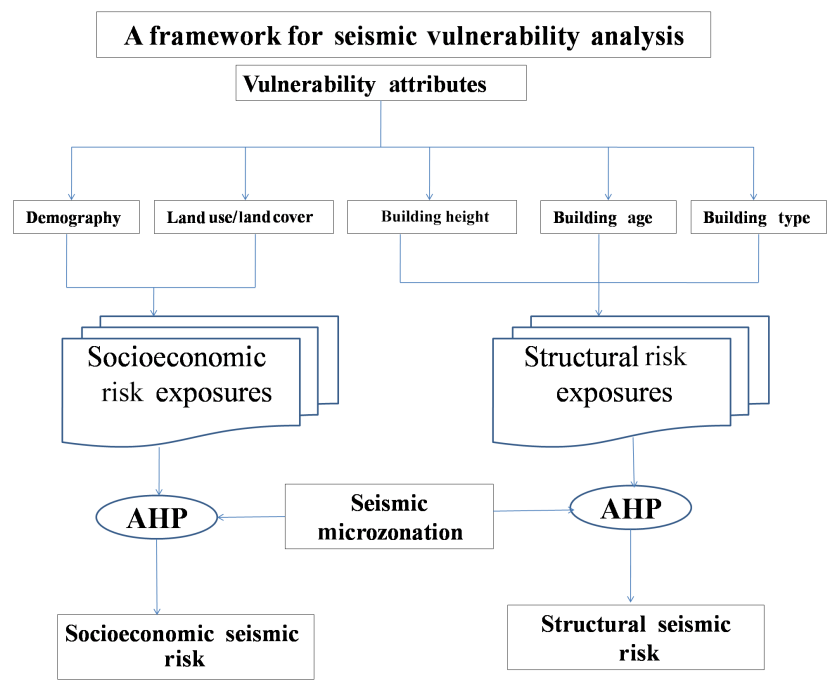

Figure 2. Seismic vulnerability assessment protocol.

while kappa is close to 0, indicating "poor" agreement (Landis and Koch, 1977). The "Margfit" procedure has also been used on each error matrix through the application of a FORTRAN code "Margfit" available in Congalton (1991). The underlying methodology utilizes an iterative proportional fitting to conform to the sum of each row and column in the error matrix to a predetermined value. A normalized accuracy is calculated by summing the values on the major diagonal and dividing it by the sum of the total values in the normalized error matrix (Congalton and Green, 1999). As a result, both the producer's and user's accuracies have been incorporated in the normalized cell value, which is based on a balanced effect of the two accuracy measures (Congalton and Green, 1999). In the present study, the structural and socioeconomic vulnerability exposures derived from satellite imagery in case of building typology and land use/land cover and that generated from Google Earth 3-D aspect for building height are used as "classified" data, while those derived through rapid visual screening from 1200 survey locations being considered as "reference" data have been used for the accuracy assessment of all the themes. For rapid visual screening a hand held GPS (Global Positioning System) is used for coordinate generation at each of the 1200 locations and the survey is conducted on the vulnerability types as has been depicted in Fig. 3 for sample RVS of building heights at four locations in the city.

The key issue for studying the earthquake vulnerability and seismic risk of urban areas is the availability of maps and statistical information that concern the infrastructure of the urban centers (Sarris et al., 2010). For best possible assessment of the vulnerability exposures and hence risk of an earthquake-prone district, it is necessary to gather maximum possible information as proposed in the HAZUS risk assessment model that require detailed inputs on structural configuration in terms of design, shape, height and number of 

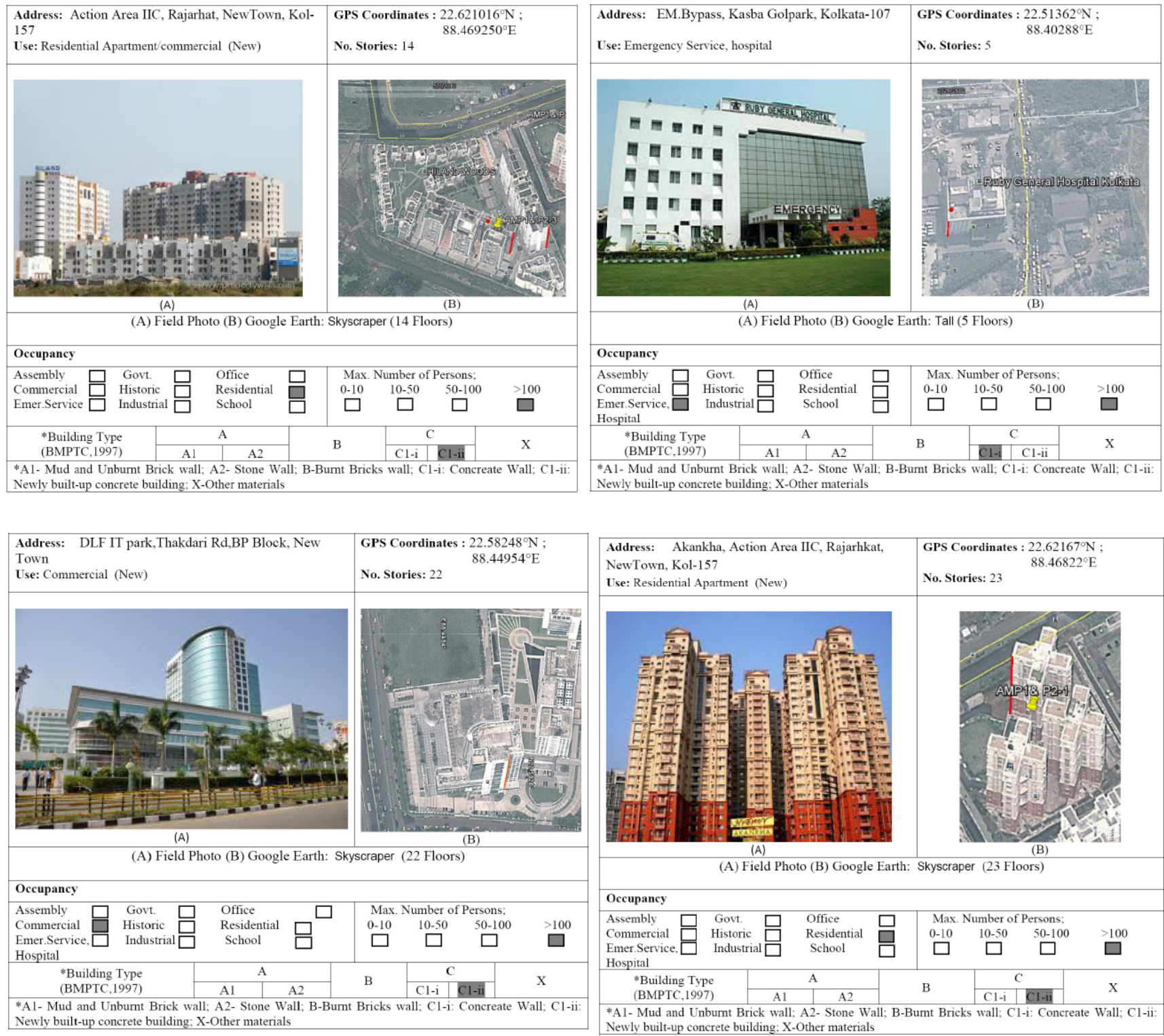

Figure 3. Rapid visual screening (RVS) survey (at about 1200 sites) for field and Google Earth comparisons of existing building height in urban Kolkata for potential seismic vulnerability assessment.

stories, building proximity, lateral strength, stiffness, ductility, foundation, material, construction practice, etc. (Sarris et al., 2010). The study is focused on building-specific analysis from building inventory of a group of buildings with similar characteristics and classifications. However,in the present investigation we proposed an alternative approach based on the information extracted from satellite imagery, Google Earth and rapid visual screening for a broader estimation of socioeconomic and structural vulnerability of the city of Kolkata and its seismic risk.

\subsection{Demography}

Population vulnerability exposure can easily be estimated from census data, which provide an average number of persons per parcel/ward and also its relation to building types. The population of urban Kolkata increased from 1.5 million in 1901 to 14 million in 2011 as illustrated in Table 1. Amongst the total population, the following groups are most vulnerable to seismic shaking: the female population, agewise population below 7 and above 65, day and nighttime population, and illiterate and unemployed population. This is well exemplified by the questionnaire for the Indian census (Census India, 2011). From Fig. 4 it is observed that the pop- 
Table 1. Population growth of urban Kolkata during 1901-2011 (Census India, 2011; http://censusindia.gov.in).

\begin{tabular}{cccc}
\hline Years & Population & $\begin{array}{c}\text { Population } \\
\text { growth }\end{array}$ & $\begin{array}{c}\text { Population } \\
\text { growth rate } \\
(\%)\end{array}$ \\
\hline 1901 & 1510008 & - & - \\
1911 & 1745198 & 235190 & 15.58 \\
1921 & 1884584 & 139386 & 7.99 \\
1931 & 2138563 & 253979 & 13.48 \\
1941 & 3621413 & 1482850 & 69.34 \\
1951 & 4669559 & 1048146 & 28.94 \\
1961 & 5983669 & 1314110 & 28.14 \\
1971 & 7420300 & 1436631 & 24.01 \\
1981 & 9194018 & 1773718 & 23.90 \\
1991 & 11021918 & 1827900 & 19.88 \\
2001 & 13205697 & 2183779 & 19.81 \\
2011 & 14112536 & 906839 & 7.6 \\
\hline
\end{tabular}

ulation density is very high in the Barabazar, Taltala, Kalidaha, Beniatola, Khidirpur, Metiaburuz and Shyambazar regions.

\subsection{Land use/land cover}

LULC provides information about the predominant urban land cover and socioeconomic attributes that can be extracted by carrying out an object-oriented LULC classification on National Atlas and Thematic Mapping Organization (NATMO) nomenclature. LULC classes are mostly defined by the alignment of buildings, streets, agricultural land, vegetation, plantation, water body, open spaces, etc. In the present study LISS-IV and PAN 2010 (NRSC Data Center, ISRO) data have been classified based on the maximum likelihood method. The LULC map of Kolkata shown in Fig. 5 depicts nine major LULC units viz. residential commercial and industrial area, river/pond/water body/canal, plantation, open space, vegetation, swampy land, dry fallow land, cultivated land and arable land. The accuracy statistics between the RVS-derived "reference" and the LISS-IV-derived "classified" maps presented in Table 2 establish the confidence level of this thematic classification.

\subsection{Building typology}

The type of materials used in construction is one of the most important attributes in evaluating vulnerability to seismic hazard. Through visual interpretation techniques using image elements such as tone, texture, shape, size, shadow, pattern, association and location, the building footprint map can be prepared with the help of poor spectral and spatial resolution imageries. Landsat TM imagery has been used in this study because of its finer spectral resolution compared to other commonly used images such as SPOT and multi-spectral scanner (MSS). However, LISS-IV imagery has also been

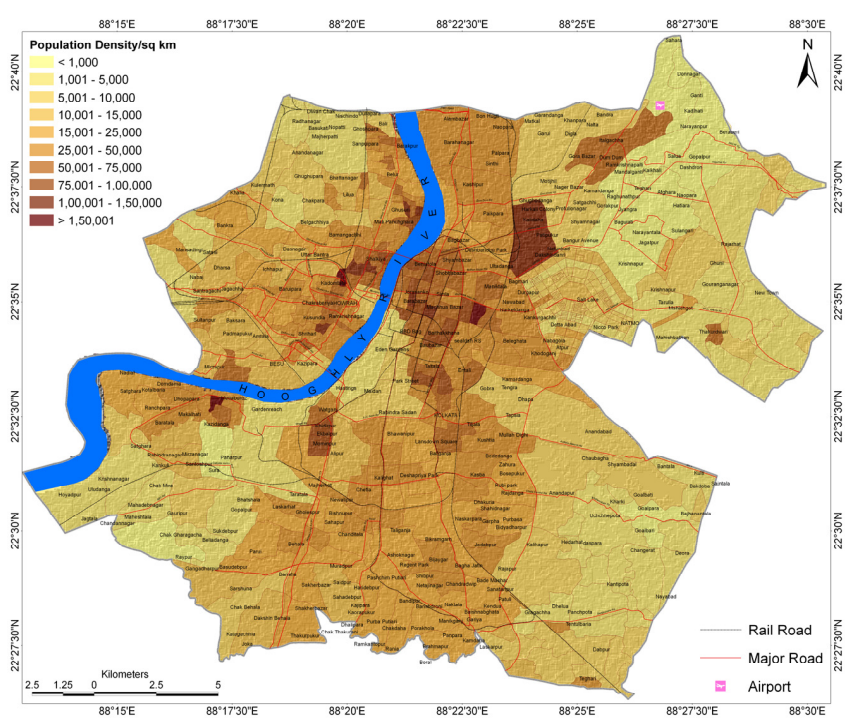

Figure 4. Population density distribution of Kolkata (after data from Census India, 2011).

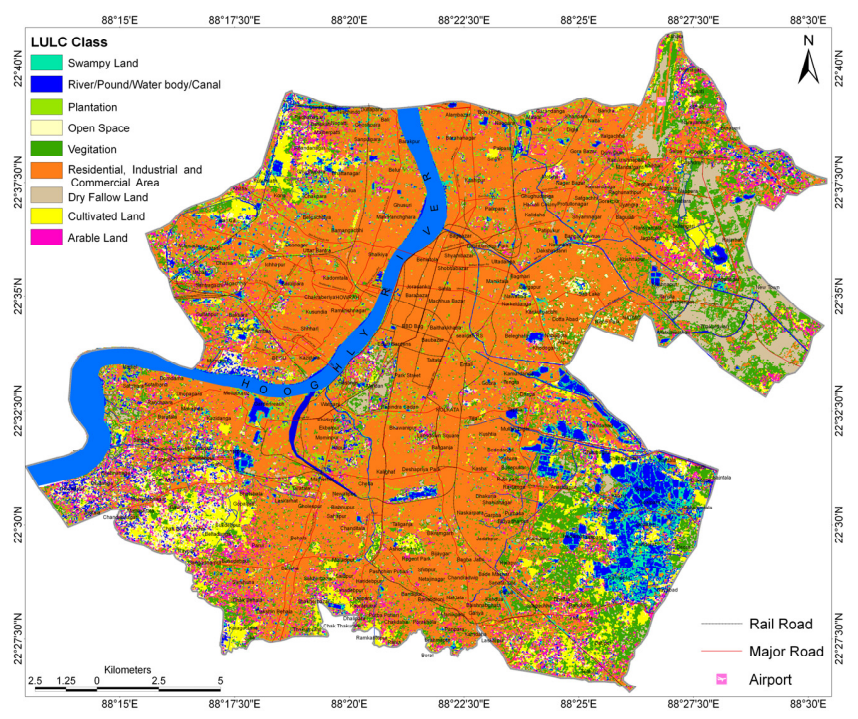

Figure 5. Land use/land cover map of Kolkata generated using LISS IV and PAN 2010 imagery.

used for its finer spatial resolution and better enhancement of urban attributes. In the present study, we have performed principal component analysis, textural analysis and the normalized differences building index (NDBI) for the identification of building materials (Geneletti and Gortea, 2003; Lu and Weng, 2005; Zhang et al., 2002; Zha et al., 2003). The building materials have been categorized into five classes (A1 is mud and non-brick wall, A2 is stone wall, B is burnt brick building/building of the large block and prefabricated type/building in natural hewn stone, $\mathrm{C} 1-\mathrm{i}$ is concrete building and C1-ii is newly built-up concrete building) according to BMTPC (1997); among them the use of reinforced concrete 
Table 2. Error matrix derived for land use/land cover mapping in Kolkata.

\begin{tabular}{|c|c|c|c|c|c|c|c|c|c|c|c|c|c|}
\hline \multicolumn{13}{|c|}{ GPS-based ground truth (reference data) } & \multirow{2}{*}{$\begin{array}{c}\text { User's accuracy } \\
(\%)\end{array}$} \\
\hline \multirow{11}{*}{ 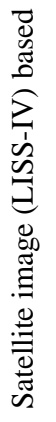 } & \multirow{11}{*}{ 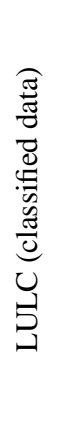 } & & RCIA & RPWC & PL & OS & VG & SL & DFL & $\mathrm{AL}$ & CL & Total & \\
\hline & & RCIA & 452 & 0 & 0 & 5 & 0 & 0 & 0 & 10 & 0 & 467 & 96.78 \\
\hline & & RPWC & 0 & 43 & 0 & 0 & 0 & 15 & 0 & 0 & 0 & 58 & 74.13 \\
\hline & & PL & 0 & 0 & 37 & 0 & 11 & 0 & 0 & 2 & 5 & 55 & 67.27 \\
\hline & & OS & 12 & 0 & 0 & 32 & 0 & 3 & 11 & 3 & 1 & 62 & 51.61 \\
\hline & & VG & 0 & 0 & 17 & 0 & 89 & 2 & 5 & 7 & 3 & 123 & 72.35 \\
\hline & & SL & 0 & 7 & 0 & 0 & 3 & 98 & 11 & 5 & 3 & 127 & 77.16 \\
\hline & & DFL & 0 & 0 & 0 & 5 & 0 & 0 & 37 & 9 & 3 & 54 & 68.51 \\
\hline & & $\mathrm{AL}$ & 17 & 0 & 0 & 3 & 5 & 7 & 13 & 71 & 18 & 134 & 52.98 \\
\hline & & CL & 0 & 0 & 2 & 1 & 9 & 3 & 5 & 11 & 85 & 116 & 73.27 \\
\hline & & Total & 581 & 50 & 56 & 46 & 117 & 128 & 82 & 118 & 118 & & \\
\hline \multicolumn{3}{|c|}{$\begin{array}{l}\text { Producer's } \\
\text { accuracy }(\%)\end{array}$} & 93.97 & 86.00 & 66.1 & 78.0 & 76.0 & 76.6 & 45.1 & 65.7 & 72.0 & & \\
\hline \multicolumn{4}{|c|}{ Overall accuracy $(\%)$} & \multicolumn{10}{|c|}{78.92} \\
\hline \multicolumn{4}{|c|}{ Normalized accuracy $(\%)$} & \multicolumn{10}{|c|}{70.00} \\
\hline \multicolumn{4}{|c|}{ Kappa value } & \multicolumn{10}{|c|}{0.733} \\
\hline \multicolumn{4}{|c|}{ Kappa variance } & \multicolumn{10}{|c|}{0.0002} \\
\hline
\end{tabular}

blocks dominates the area, as depicted in Fig. 6. The vulnerability curves for the observed damage due to 1934 BiharNepal earthquake of $M_{\mathrm{w}}=8.1$ (GSI, 1939) for reinforced cement concrete (RCC), steel, masonry and non-engineered structures in Kolkata and adjoining regions have been constructed following Sinha and Adarsh (1999) and presented in Fig. 7. The accuracy statistics between the RVS-derived "reference" and the LISS-IV 2010 and Landsat-TM-2010derived "classified" maps have been presented in Table 3.

\subsection{Building age}

The urban population of Kolkata has grown tremendously in the last 4 decades. This fast rate of increase in urban population is mainly due to large-scale migration of people from rural and smaller towns to bigger cities in search of better employment opportunities and lifestyle. Remote sensing imagery is ideally used for monitoring and detecting urban land cover changes that occur frequently in urban and periurban areas as a consequence of incessant urbanization (Zha et al., 2003). Land covers in urban areas tend to change more drastically over a short period of time than elsewhere because of rapid economic development and urban sprawl. In the present study, the built-up areas were extracted from the Landsat MSS (1975, 1980), TM (1985, 1990, 2005, 2010) and ETM (2000) classified images of seven different periods in order to monitor the dynamic changes of urban sprawl (Small, 2002; Zhang et al., 2002). For this purpose, we used NDBI for classification of built-up areas (Zha et al., 2003).

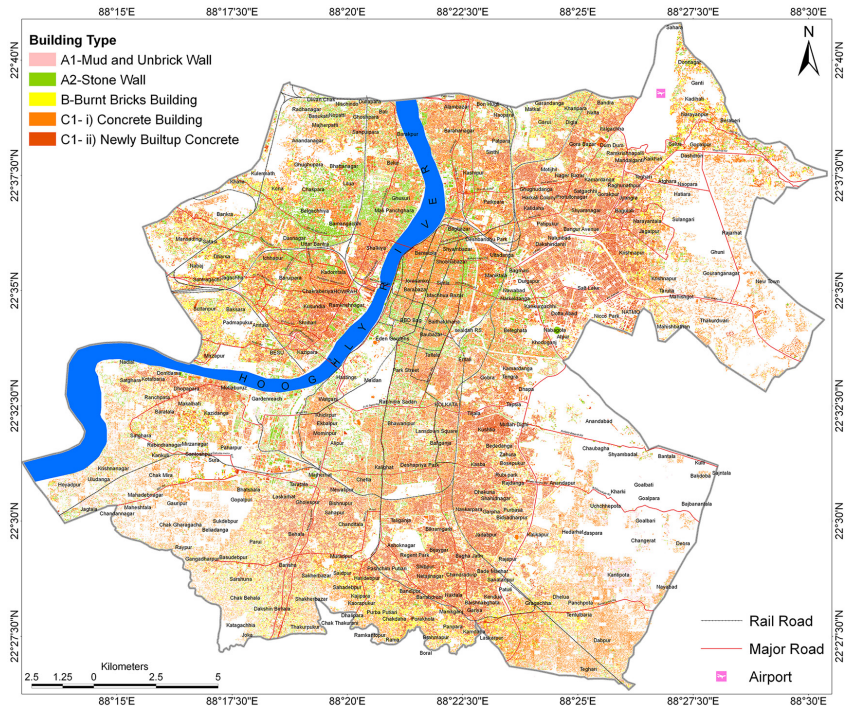

Figure 6. Building typology distribution map of Kolkata derived using LISS IV 2010 and Landsat TM 2010 imagery.

Change detection analyses describe the differences between the images of the same scene at different periods of time. The building age/urban growth of Kolkata as depicted in Fig. 8 has been estimated using change detection technique by using ERDAS IMAGINE 8.5 software package. For map validation purposes we selected a sample block in the 


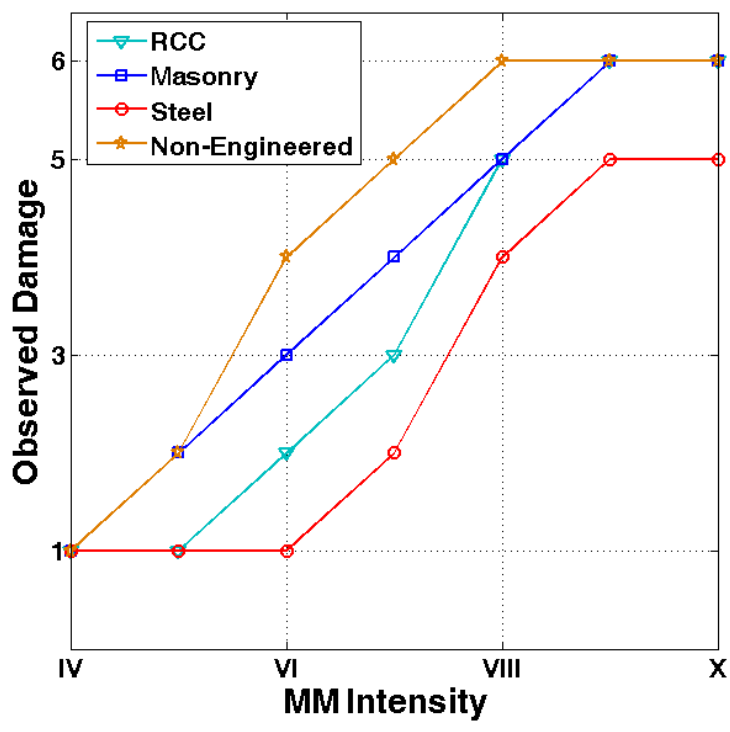

Figure 7. Vulnerability curves for observed damage inflicted by the 1934 Bihar-Nepal earthquake of $M_{\mathrm{W}}=8.1$ (GSI, 1939) on various building typology in Kolkata and adjoining regions, based on Sinha and Adarsh (1999).

Table 3. Error matrix derived for building typology in Kolkata.

\begin{tabular}{llllllllll}
\hline \multicolumn{1}{c}{ Rapid visual screening based building typology } \\
(reference data)
\end{tabular}

Newtown financial and infrastructural hub of Kolkata where Landsat TM and Google Earth imageries of 2005 and 2010 have been considered as "classified" and "reference" data sets for both the categories for the assessment of urban growth and its corresponding error statistics. Figure 9 depicts the urban expansion during the period 2005-2010 based on both Landsat TM and Google Earth Imageries. The associated error matrix is given in Table 4. It has been observed that the optimal lifetime of structures in Kolkata is between 40 and 50 years. The urban expansion has been divided into seven clusters: younger than $5,10,20,25,30,35$ and older than 35 years, as depicted in Fig. 8. The older buildings

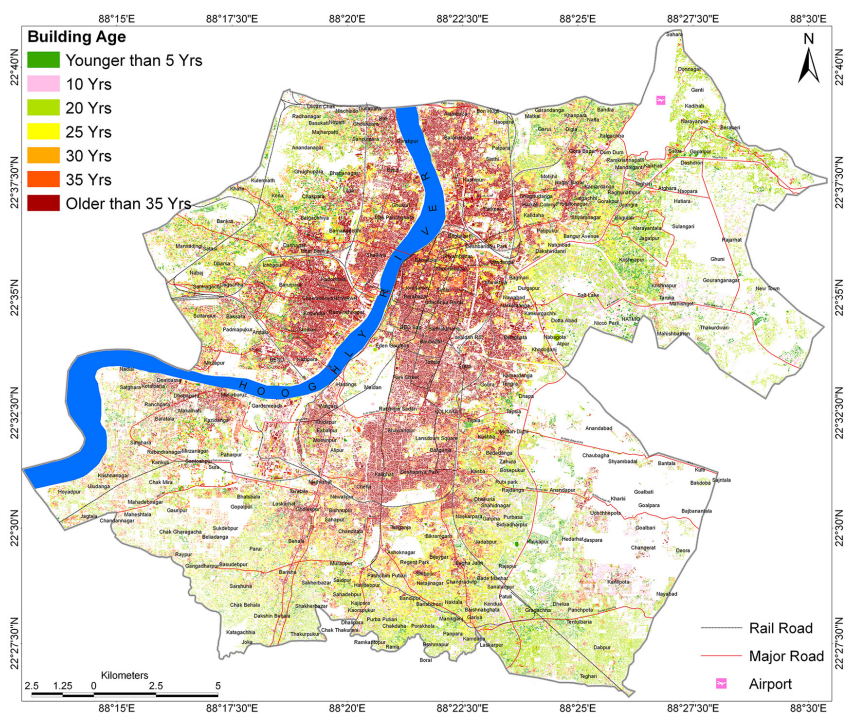

Figure 8. Building age classification map of Kolkata using multitemporal Landsat MSS (1975, 1980), TM (1985, 1990, 2005, 2010) and ETM (2000) data for the period of 1975-2010 wherein the older buildings ( $>35$ years) have been adopted from "Atlas of the City of Calcutta and its Environs" (Kundu and Aag, 1996).

( $>35$ years) have been adopted from "Atlas of the city of Calcutta and its Environs" (Kundu and Aag, 1996). However, older buildings are likely to be vulnerable to severe damages and even subjected to total collapse under strong seismic excitations. There are many aged, ill-conditioned, closely spaced structures in Kolkata which also seem to be highly vulnerable due to seismic threat.

\subsection{Site-structure quasi-resonance and possibility of damage}

The response of a building to seismic shaking at its base depends on the design quality of construction. The most important factor is the height of the building. The type of shaking and the frequency of shaking depend on the structure as well as the site of its construction. The fundamental frequency of structures may range from about $2 \mathrm{~Hz}$ for a low-rise structure up to about four stories and between 0.5 and $1 \mathrm{~Hz}$ for tall buildings/skyscrapers from 10 to 20 stories (Kramer, 1996). The tall buildings tend to amplify the longer period motions compared to small buildings. Each structure has a resonance frequency that is the characteristic of the building. Therefore, in developing the design strategy for a building, it is desirable to estimate the fundamental periods both of the building and the site on which it is to be constructed so that a comparison can be made to understand the possibility of quasi-resonance phenomenon. In the present study, Google Earth and about 1200 ground-truth ground control points have been used for visual identification of building height using a 3-D aspect and its validation. In Fig. 10 the building height map of Kolkata is 

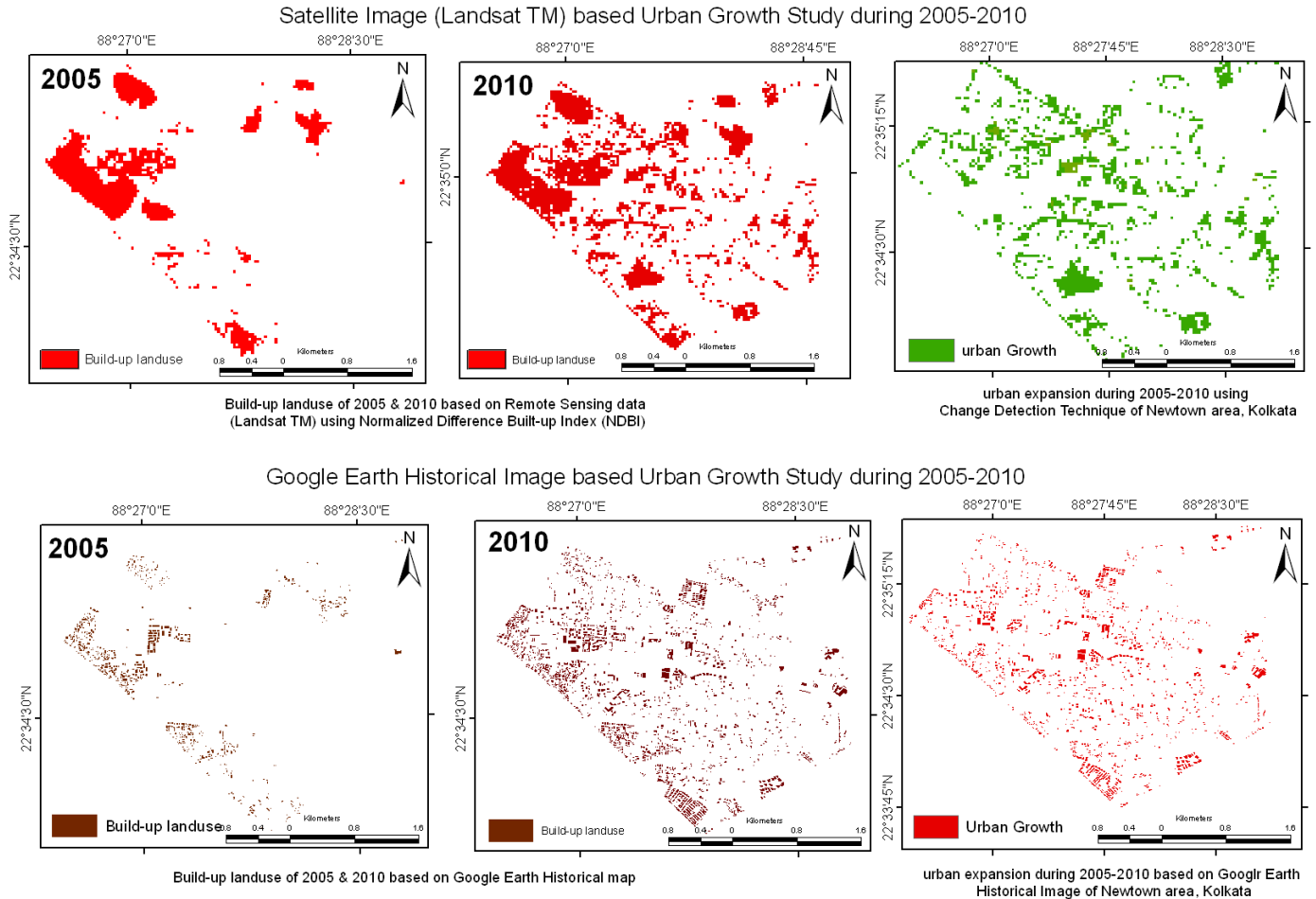

Figure 9. Urban expansion during the period 2005-2010 based on both Landsat TM and Google Earth imageries.

Table 4. Error matrix derived for building growth/age during 2005-2010 in Newtown, Kolkata.

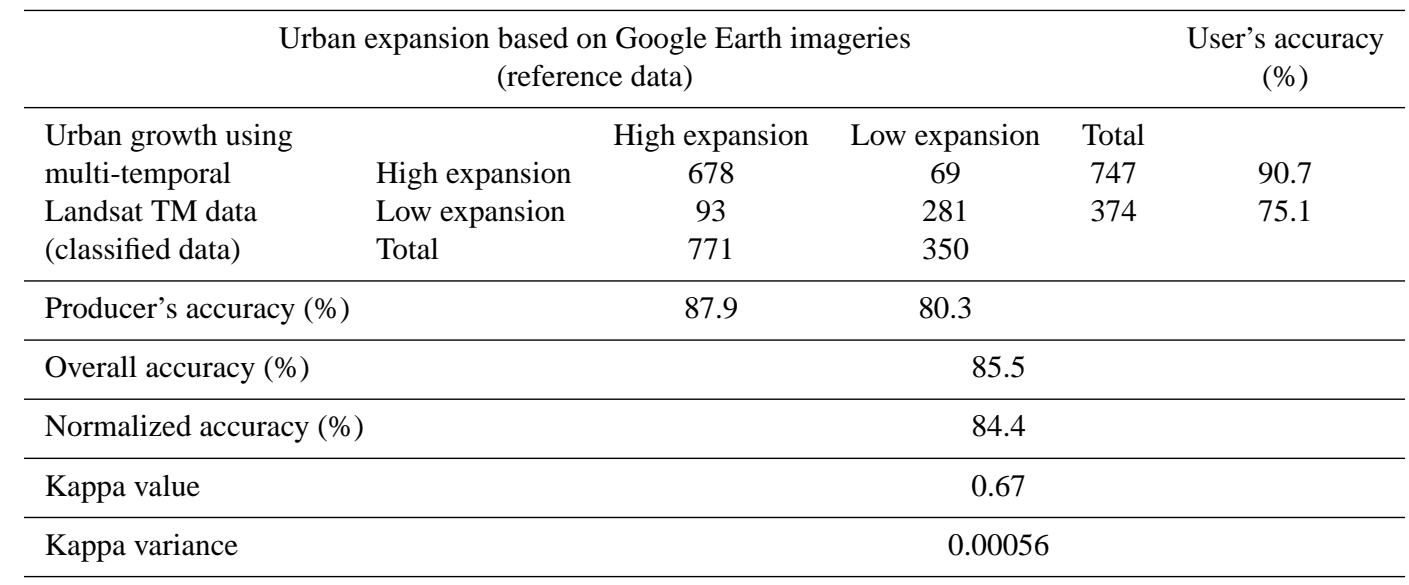

presented. The accuracy statistics between the RVS-derived "reference" and the Google-Earth-derived "classified" maps have been presented in Table 5. The building heights have been categorized into five classes: houses with 1 floor, buildings with 2-4 floors, tall buildings with 5-8 floors, multistoried buildings with 9-10 floors and skyscrapers with $>10$ floors. Therefore, the approximate fundamental natural period of vibration $\left(T_{\mathrm{a}}\right)$, in seconds, has been estimated using the empirical relation (BIS, 2002):

$$
\begin{aligned}
T_{\mathrm{a}} & =0.075 h^{0.75} \quad \text { for RCC frame building } \\
& =0.085 h^{0.75} \quad \text { for steel frame building } \\
& =\frac{0.09 h}{\sqrt{d}} \quad \text { all other buildings, }
\end{aligned}
$$

where $T_{\mathrm{a}}$ is the fundamental period of vibration in seconds, $h$ is the height of the building in meters and $d$ is the base dimension of building at plinth level in meters, along the considered direction of the lateral force. 
Table 5. Error matrix derived for building height in Kolkata.

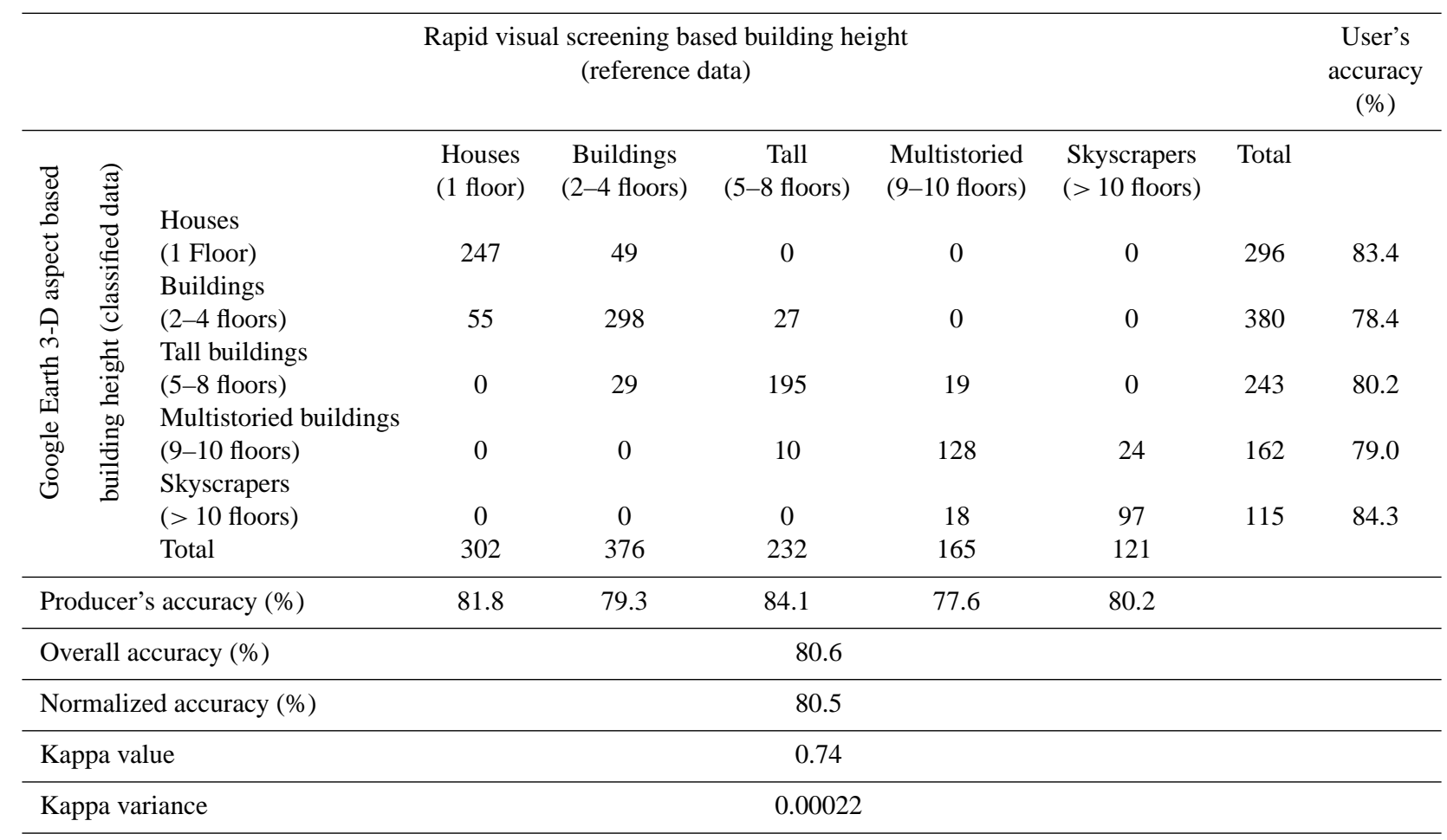

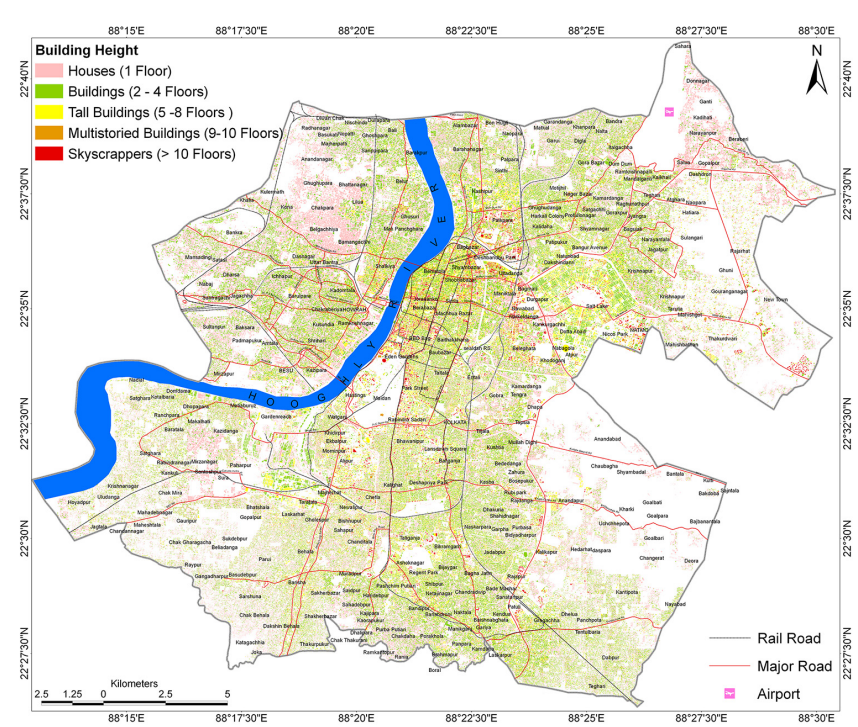

Figure 10. Building height distribution map of Kolkata using Google Earth 2012 imagery.
The site fundamental period has been estimated from microtremor horizontal-to-vertical $(H / V)$ power spectral ratio (HVSR) (Nakamura, 1989) based on the following equation:

$H / V_{\text {spectral ratio }}=\sqrt{\frac{\sum P_{\mathrm{NS}}(\omega)+\sum P_{\mathrm{EW}}(\omega)}{\sum P_{\mathrm{V}}(\omega)}}$,

where $P_{\mathrm{NS}}(\omega), P_{\mathrm{EW}}(\omega)$ and $P_{\mathrm{V}}(\omega)$ are the power spectra of NS, EW and the vertical components, respectively, summation being taken over the data blocks. The $H / V$ response curves obtained from the microtremor survey reflect the geology and soil properties of the test site. Lermo and Chávez-García (1993) examined the relevance of HVSR for weak and strong motion earthquake records and found good agreement among the soil resonance frequencies. Using 1-D models of shear wave velocity, they validated the applicability of HVSR. In the present study, ambient noise data acquired using SYSCOM MR2000 during the extensive field survey of 2012-2013 at 1200 locations in the city have been processed using View2002 and GEOPSY software (www.geopsy.org). The predominant frequency distribution map shown in Fig. 11 is prepared on GIS platform exhibiting a variation between 0.5 and $3.1 \mathrm{~Hz}$. The proximity of predominant frequency of the soil column and the natural frequency of lifeline facilities indicates higher vulnerability of the built-up environment owing to resonance effects (Nath and Thingbaijam, 2009). Usually care is taken that the natural period of vibration of any structure should not coincide with the predominant period of earthquake excitations 


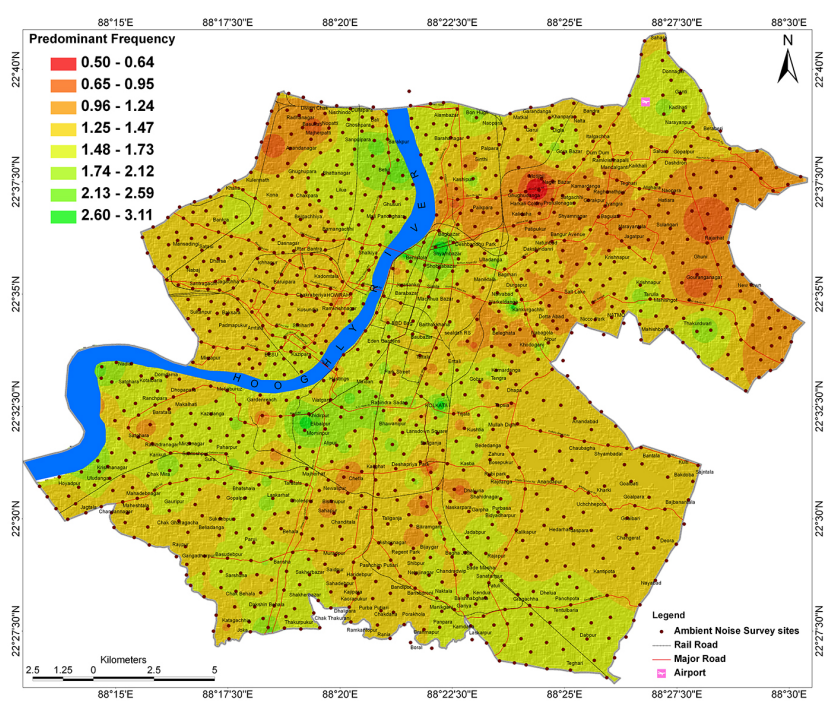

Figure 11. Spatial distribution of predominant frequency in Kolkata as obtained from an ambient noise survey during the extensive field survey of 2012-2013 at 1200 locations and processing of those by Nakamura ratio.

in order to avoid resonance that may occur, causing damage to even strongest structures which may eventually collapse (BIS, 2002). Figure 12 presents the difference between the structure's natural period of vibration and the fundamental period of the respective site on which the structure stands, indicating damage possibilities of existing structures/logistics due to the impact of an earthquake - the larger the difference, the lesser the possibility of damage or destruction is.

\section{Seismic hazard microzonation of Kolkata}

Seismic hazard can be estimated by analyzing past earthquake activity in the region, evidence of stress-bearing capacity of structures within the fault area and how seismic waves travel through the crust and the overlying soils beneath the sites (Panahi et al., 2014). It is noted that at the time of an earthquake, in addition to PGA, the incidence of soil liquefaction and slope failure are the secondary phenomena which can increase seismic vulnerability and hence damage. Multi-criteria assessment of seismic hazard leading to seismic microzonation is the key factor to understanding the overall seismic risk of a region (Anbazhagan et al., 2010). The hazard mapping is achieved through the multi-criteriabased decision support system formulated by Saaty (1980) as AHP. The hazard themes pertaining to the study region materialized as thematic layers on the GIS platform are (i) PGA with $10 \%$ probability of exceedance in 50 years at surface, (ii) LPI, (iii) NEHRP SC, (iv) SEC, (v) GM and (vi) groundwater table (GW) fluctuation as shown in Fig. 13a-f. In the present study, ArcGIS 9.3 is used for the purpose of thematic

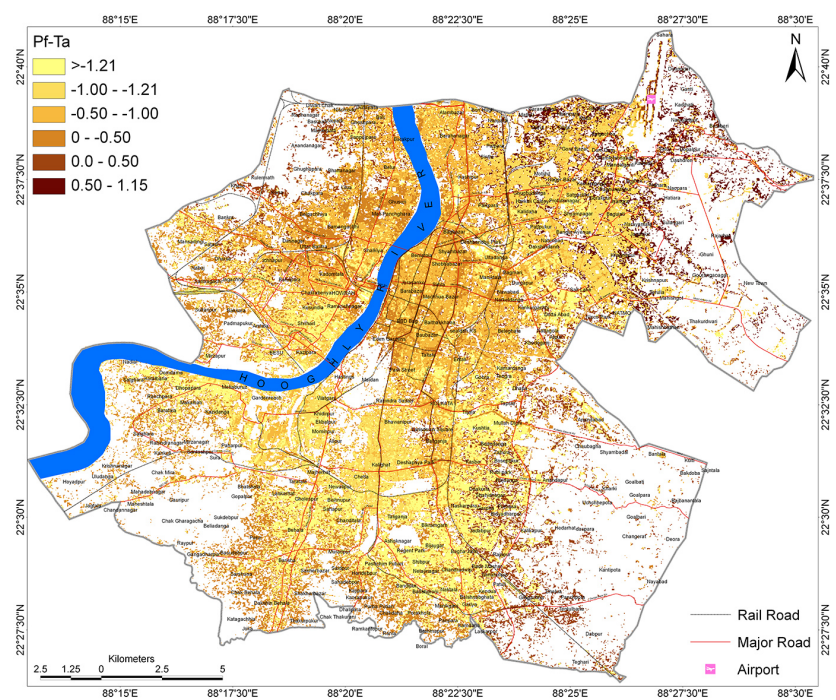

Figure 12. The difference between the natural period of vibration of structures and the fundamental period of respective sites, indicating damage possibilities of existing structures/logistics.

mapping through vector layer generation and its spatial analysis.

The major geomorphological units present in Kolkata are deltaic plain, inter-distributary marsh, paleo-channels, younger levee adjacent to the River Hoogly and older levee on both the sides of the Adi Ganga (Roy et al., 2012) as depicted in Fig. 13a. Site classification of Kolkata performed using in-depth geophysical and geotechnical investigations from 350 borehole data based on NEHRP, USGS and FEMA nomenclature places the city in D1 $\left(V_{\mathrm{s}}^{30}: 180-240 \mathrm{~m} \mathrm{~s}^{-1}\right)$, D2 $\left(V_{\mathrm{s}}^{30}: 240-300 \mathrm{~m} \mathrm{~s}^{-1}\right), \mathrm{D} 3\left(V_{\mathrm{s}}^{30}: 300-360 \mathrm{~m} \mathrm{~s}^{-1}\right)$ and $\mathrm{E}\left(V_{\mathrm{s}}^{30}\right.$ : $<180 \mathrm{~m} \mathrm{~s}^{-1}$ ) classes, as shown in Fig. 13b. Based on the proportions of sand, silt and clay-sized particles obtained from 350 boreholes in Kolkata, the bottom sediments have been classified according to Shepard's diagram (O’Malley, 2007) and exhibit highly liquefiable sediments viz. sand, sand-silt clay, sandy clay, silty sand and silty clay up to about $\sim 5 \mathrm{~m}$ as shown in Fig. 13c. The probabilistic seismic hazard assessment at surface-consistent level performed by propagating the bedrock ground motion with $10 \%$ probability of exceedance in 50 years through a 1-D sediment column using an equivalent linear analysis of an otherwise nonlinear system predicts a peak ground acceleration variation from 0.176 to $0.253 \mathrm{~g}$ in the city, as depicted in Fig. 13d. Groundwater table depth is among the major contributors affecting the stability of the soil column. The water table depths obtained from 350 boreholes calibrated with post-monsoon piezometer survey in the city have been used to generate a water table depth variation map of the city, shown in Fig. 13e, depicting water table fluctuations between 0.1 and $7.7 \mathrm{~m}$ depth. There had been evidence of wide-spread liquefaction in Kolkata triggered by the 1934 Bihar-Nepal earthquake of $M_{\mathrm{w}}=8.1$ 


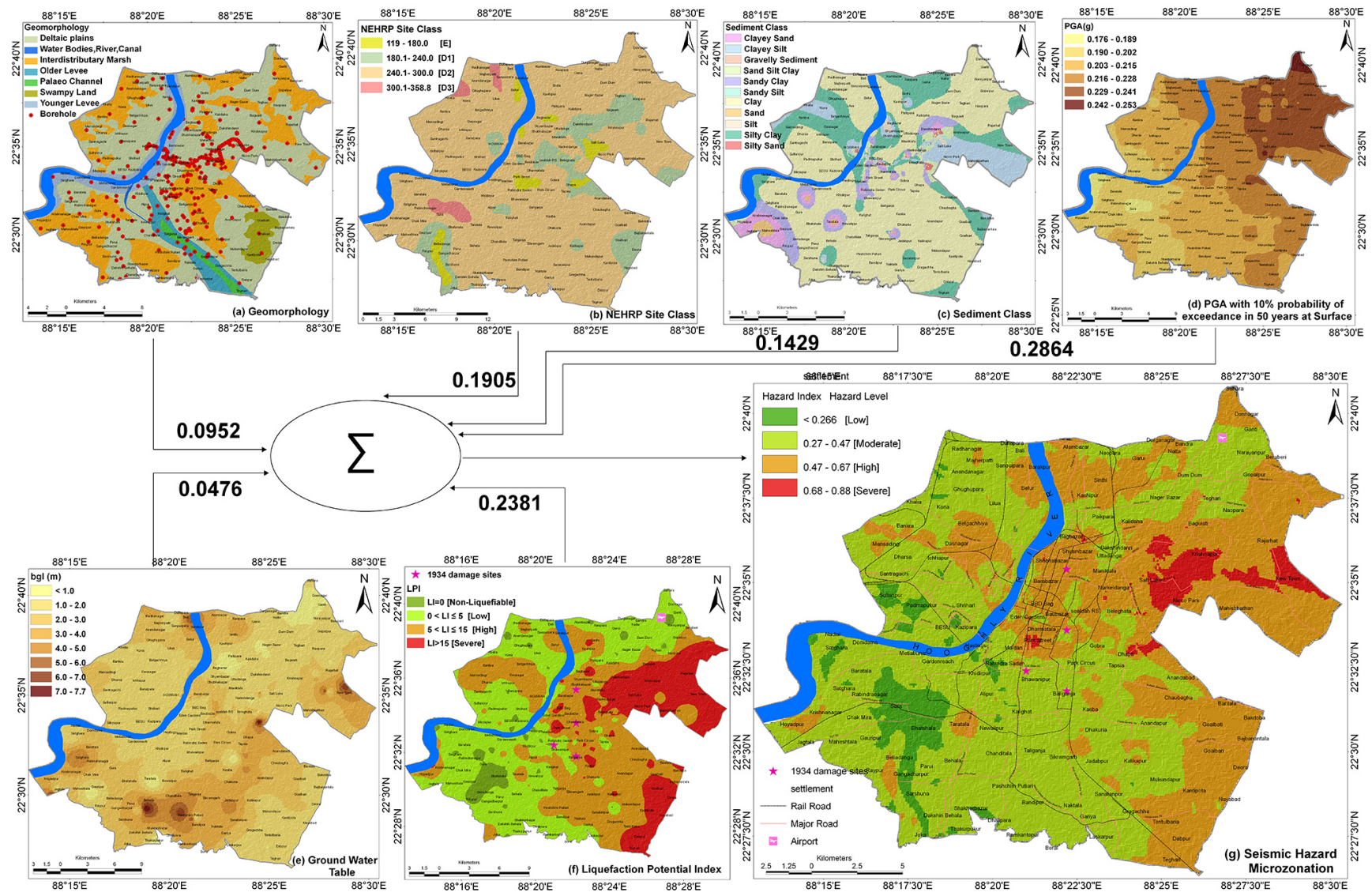

Figure 13. Seismic hazard microzonation protocol for Kolkata showing the weights assigned to each theme, i.e., (a) geomorphology, (b) NEHRP site class, (c) sediment class, (d) spatial distribution of PGA in Kolkata with $10 \%$ probability of exceedance in 50 years at surface, (e) groundwater table and (f) liquefaction potential index (LPI) distribution, which are integrated using an aggregation method from the GIS platform; (g) seismic hazard microzonation map of Kolkata (see electronic supplement for a higher resolution version of this diagram).

(GSI, 1939). Therefore, soil liquefaction in terms of factor of safety against liquefaction is considered one of the major contributors of induced seismic hazard potential in Kolkata and is, therefore, also used in the present microzonation protocol. The standard methodology given by Youd et al. (2001), Idriss and Boulanger (2006) and Iwasaki et al. (1982) that uses a corrected SPT-N value has been employed for the estimation of liquefaction susceptibility in the city considering surface PGA distribution with $10 \%$ probability of exceedance in 50 years. LPI values have been classified according to Iwasaki et al. (1982) as non-liquefiable $(\mathrm{LPI}=0)$, low $(0<\mathrm{LPI}<5)$, high $(5<\mathrm{LPI}<15)$ and severe $(\mathrm{LPI}>15)$, as shown in Fig. 13f. Each theme has been described in detail in Nath et al. (2014).

The corresponding weights and the ranks of each thematic layer and the feature ranks thereof are assigned values accordingly to the apparent contribution of the layers to the overall seismic hazard (Nath, 2004). All the geo-referenced thematic layers are integrated step by step using the aggregation method in GIS to generate seismic hazard microzonation
(SHM) map as

$$
\begin{aligned}
\mathrm{SHM} & =\left[\mathrm{PGA}_{\mathrm{w}} \mathrm{PGA}_{\mathrm{r}}+\mathrm{LPI}_{\mathrm{w}} \mathrm{LPI}_{\mathrm{r}}+\mathrm{SC}_{\mathrm{w}} \mathrm{SC}_{\mathrm{r}}\right. \\
& \left.+\mathrm{SEC}_{\mathrm{w}} \mathrm{SEC}_{\mathrm{r}}+\mathrm{GM}_{\mathrm{w}} \mathrm{GM}_{\mathrm{r}}+\mathrm{GW}_{\mathrm{w}} \mathrm{GW}_{\mathrm{r}}\right] / \sum w,
\end{aligned}
$$

where $w$ represents the normalized weight of a theme and $r$ is the normalized rank of a feature in the theme. Thereafter, a $3 \times 3$ "majority filter" has been applied to the SHM as a post-classification filter to reduce the high frequency variation. SHM is a dimensionless quantity that helps to index the probability of seismic hazard and hence the microzonation of a region on a qualitative scheme such as "low", "moderate", "high" and "severe". The probabilistic seismic hazard microzonation map of Kolkata is shown in Fig. 13g. Four broad divisions have been identified with a hazard index (HI) of $0.68<\mathrm{HI} \leq 0.88$, indicating severe hazard condition in the Salt Lake area; $0.47<\mathrm{HI} \leq 0.68$, indicating a high hazard condition mostly in Rajarhat and New Town areas of the expanding city; $0.27<\mathrm{HI} \leq 0.47$, indicating moderate hazard condition in most parts of south and west Kolkata; and $\mathrm{HI}<0.27$,representing a low hazard condition. The dam- 
age distribution due to the 1934 Bihar-Nepal earthquake of $M_{\mathrm{w}}=8.1$ is reported to have induced an MM intensity VIVII in Kolkata (GSI, 1939), mostly identified in the moderate to high hazard zone (marked by an asterisk).

\section{Multi-criteria seismic risk assessment}

Ishita and Khandaker (2010) performed seismic vulnerability assessment using AHP and GIS, wherein various themes such as building floors, building types, building age, resident population, population density, land use/land cover were used to evaluate seismic vulnerability. The steps usually followed in the vulnerability assessment are as follows. Highrisk areas are identified by convolving seismic hazard microzonation with vulnerability exposures in the GIS environment using AHP (Reveshty and Gharakhlou, 2009; Aghataher et al., 2008; Qunlin et al., 2013; Sarris et al., 2010). The AHP method avails to investigate the consistency of judgments to determine the significance of relative weight of factors (Reveshty and Gharakhlou, 2009). To determine the degree of consistency in judgments, a consistency ratio is also measured from the AHP matrix. In the present investigation, AHP is used for the estimation of weights of various factors of vulnerability exposures for the computation of risk index in an attempt to generate a multi-criteria risk evolution protocol in both the socioeconomic and structural perspectives. A combination of spatial/non-spatial exposures against earthquakes, the degree of vulnerability of each building element in terms of its typology, height and age and the socioeconomic exposures has been measured. The associated features are ranked or scored within each theme. The initial integral ranking, $X_{j}$, is normalized to ensure that no layer exerts an influence beyond its determined weight using the following relation (Nath, 2004):

$X_{j}=\frac{R_{j}-R_{\min }}{R_{\max }-R_{\min }}$,

where $R_{j}$ is the row score and $R_{\max }$ and $R_{\min }$ are the maximum and minimum scores of a particular layer.

The socioeconomic risk elements, i.e., population density (PD) and LULC, are integrated with the seismic hazard microzonation theme to demarcate the most vulnerable zones in the view of socioeconomic activities of the region. The socioeconomic risk index (SERI) is calculated as

$\mathrm{SERI}=\left[\mathrm{SHM}_{\mathrm{w}} \mathrm{SHM}_{\mathrm{r}}+\mathrm{PD}_{\mathrm{w}} \mathrm{PD}_{\mathrm{r}}+\mathrm{LULC}_{\mathrm{w}} \mathrm{LULC}_{\mathrm{r}}\right] / \sum w$.

The ranks and weights for socioeconomic vulnerability exposures over seismic hazard microzonation are illustrated in Table 6. The concept of social vulnerability helps to identify those characteristics and experiences of individuals and communities that enable them to respond and to recover from earthquake hazards (Cutter et al., 2003). The socioeconomic seismic risk map of Kolkata is depicted in Fig. 14. Four broad divisions of SERI have been identified with the following risk indexes: $0.75<\mathrm{SERI} \leq 1.0$, indicating severe risk condition in Salt Lake and patches of central Kolkata area; $0.50<\mathrm{SERI} \leq 0.75$, indicating high seismic risk in most of the central and northern Kolkata; $0.25<$ SERI $\leq 0.50$, indicating moderate risk in the most part of southern, northeastern and western Kolkata; and SERI $<0.25$, presenting a completely risk-free regime.

The structural risk elements, namely building typology (BT), building height (BH) and building age/growth (BA), have been integrated with the SHM depending on their contribution towards seismic vulnerability. The structural risk index (SRI) due to the structural risk exposures over the SHM are estimated as

$\mathrm{SRI}=\left[\mathrm{SHM}_{\mathrm{w}} \mathrm{SHM}_{\mathrm{r}}+\mathrm{BT}_{\mathrm{w}} \mathrm{BT}_{\mathrm{r}}+\mathrm{BH}_{\mathrm{w}} \mathrm{BH}_{\mathrm{r}}+\mathrm{BA}_{\mathrm{w}} \mathrm{BA}_{\mathrm{r}}\right] / \sum w$.

The ranks and weights for structural vulnerability exposures over seismic hazard microzonation are illustrated in Table 7. To determine the most and least structurally vulnerable areas, the SRI scores are mapped as $<0.25$ (low vulnerability) to $\sim 1$ (high vulnerability) as shown in Fig. 15. Four broad divisions have been identified with SRI: $0.75<\mathrm{SRI} \leq 1.0$, indicating severe risk condition in Salt Lake area; $0.50<\mathrm{SRI} \leq 0.75$, indicating high risk mostly in central Kolkata; $0.25<\mathrm{SRI} \leq 0.50$, indicating moderate risk in the most part of west Kolkata; and SRI $<0.25$, presenting a completely risk-free regime. From the depiction of Fig. 15, it is easier to identify the most vulnerable buildings and, therefore, the suggestion for their preventive measures. In Kolkata, most of the structural vulnerability indexes range from 0.25 to 0.75 indicating moderate to high vulnerability level. Detailed analyses and ground truthing reveal that most of the buildings in the city are 1-4 storied and the resonance frequency of the soil column is between 1.0 and $2.0 \mathrm{~Hz}$. It is observed that an index $>0.5$ is of higher vulnerability in terms of both height and severity of structural damage, being constructed on swamps and artificially non-engineered fills. In central Kolkata most of the buildings exhibit high structural vulnerability because of age $(80 \%>35$ years $)$ and unplanned construction. The damage distribution due to the Great 1934 Bihar-Nepal earthquake of $M_{\mathrm{w}}=8.1$ is identified in the severe to high-risk zones (marked by an asterisk). The detailed seismic vulnerability attributions are presented in Table 8.

In the present study, we have also calculated the design horizontal seismic coefficient $\left(A_{\mathrm{h}}\right)$ for the existing structures by the following expression (BIS, 2002):

$A_{\mathrm{h}}=Z_{\mathrm{F}} I S_{\mathrm{a}} / 2 R g$,

where $Z_{\mathrm{F}}$ is the zone factor (taken from Nath et al., 2014), $I$ is the importance factor, depending upon the functional use of the structures, $R$ is the response reduction factor, depending on the perceived seismic damage performance of the structure, and $S_{\mathrm{a}} / g$ is the average response acceleration coefficient for rock or soil sites (Nath et al., 2014). BIS (2002) 
Table 6. Normalized weights and ranks assigned to respective themes and the features of socioeconomic risk attributes for thematic integration on GIS.

\begin{tabular}{lcccc}
\hline Themes & Weight & Attributes & Rating & Normalized rating \\
\hline Seismic hazard microzonation & 0.50 & Low & 1 & 0.0000 \\
$(\mathrm{SHM})$ & & Moderate & 2 & 0.3333 \\
& & High & 3 & 0.6666 \\
& & Severe & 4 & 1.0000 \\
\hline Population density & $<1000$ & 1 & 0.0000 \\
$\left(\mathrm{~km}^{2}\right)$ & 0.33 & 2 & 0.1111 \\
& & $1001-5000$ & 3 & 0.2222 \\
& $5001-10000$ & 4 & 0.3333 \\
& $10001-15000$ & 5 & 0.4444 \\
& $15001-25000$ & 6 & 0.5556 \\
& $25001-50000$ & 7 & 0.6667 \\
& & $50001-75000$ & 8 & 0.7778 \\
& $75001-100000$ & 9 & 0.8889 \\
& & $100001-150000$ & 10 & 1.0000 \\
\hline Land use/land cover & $>150$ 000 & 1 & 0.0000 \\
& & Water body, pond, river, canal & 2 & 0.1250 \\
& & Open space & 3 & 0.2500 \\
& Swampy land & 4 & 0.3750 \\
& Dry fallow land & 5 & 0.5000 \\
& Vegetation & 6 & 0.6250 \\
& Plantation & 7 & 0.7500 \\
& Arable land & 8 & 0.8750 \\
& Cultivated land & 9 & 1.0000 \\
\hline
\end{tabular}

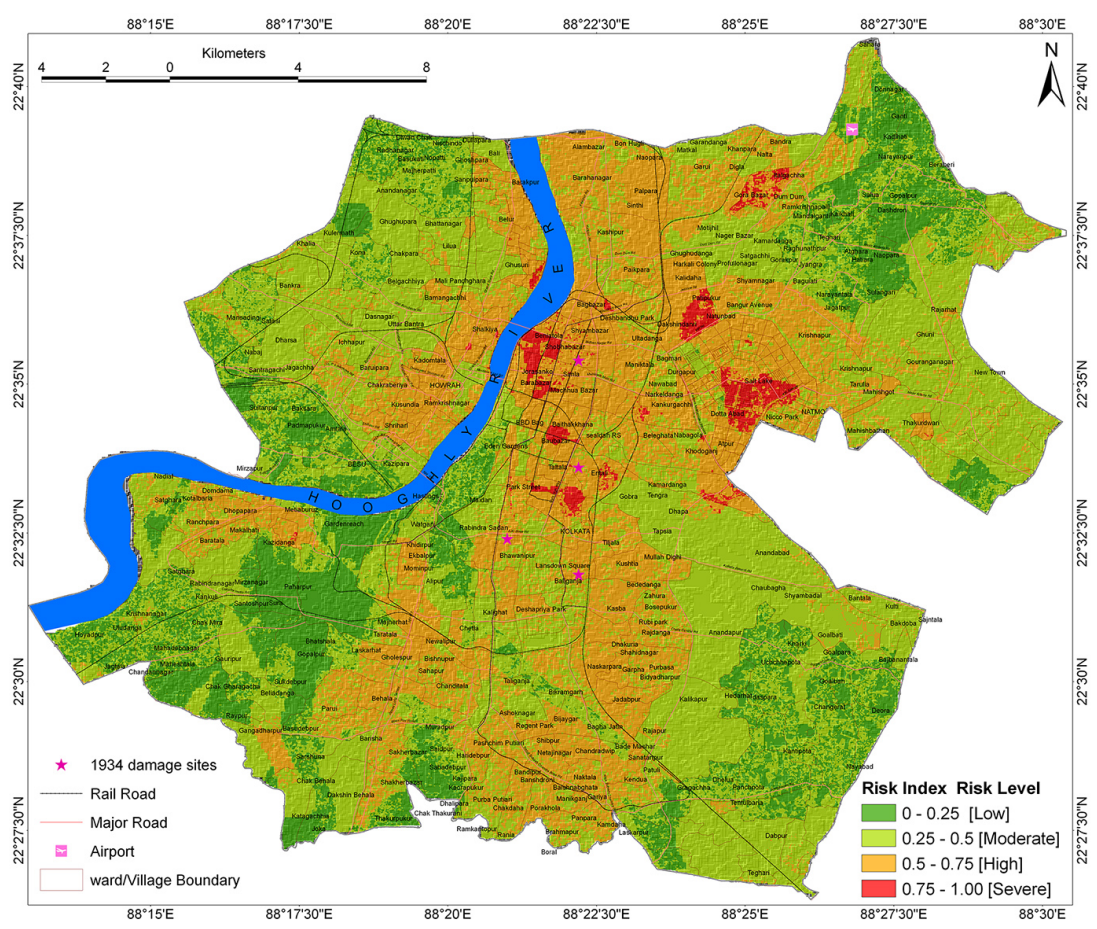

Figure 14. Probabilistic seismic socioeconomic risk map of Kolkata. Four broad divisions have been identified with risk index (SERI) defined as $0.75<\mathrm{SERI} \leq 1.0$,indicating "severe" risk condition in Salt Lake area and a patch at central Kolkata; $0.50<\mathrm{SERI} \leq 0.75$, indicating "high" risk in central and north Kolkata; $0.25<$ SERI $\leq 0.50$, indicating "moderate" risk in the most part of southeast, northeast and west Kolkata; and SERI $<0.25$, presenting a completely risk-free regime. The damage distribution due to the 1934 Bihar-Nepal earthquake of $M_{\mathrm{W}}=8.1$ (GSI, 1939) is identified in the high-risk zone (marked by an asterisk). 
Table 7. Normalized weights and ranks assigned to respective themes and the features of structural risk attributes for thematic integration on GIS.

\begin{tabular}{|c|c|c|c|c|}
\hline Themes & Weight & Attributes & Rating & Normalized rating \\
\hline \multirow{4}{*}{$\begin{array}{l}\text { Seismic hazard microzonation } \\
\text { (SHM) }\end{array}$} & \multirow[t]{4}{*}{0.40} & Low & 1 & 0.0000 \\
\hline & & Moderate & 2 & 0.3333 \\
\hline & & High & 3 & 0.6666 \\
\hline & & Severe & 4 & 1.0000 \\
\hline \multirow[t]{5}{*}{ Building typology } & \multirow[t]{5}{*}{0.30} & A1-mud and unburnt brick wall & 1 & 0.0000 \\
\hline & & A2-stone wall & 2 & 0.2500 \\
\hline & & B-burnt bricks building & 3 & 0.5000 \\
\hline & & $\mathrm{C} 1-\mathrm{i}$ : concrete building & 4 & 0.7500 \\
\hline & & C1-ii: newly build concrete building & 5 & 1.0000 \\
\hline \multirow{5}{*}{ Building height } & \multirow[t]{5}{*}{0.20} & Houses (1 floor) & 1 & 0.0000 \\
\hline & & Buildings (2-4 floors) & 2 & 0.2500 \\
\hline & & Tall buildings ( $5-8$ floors) & 3 & 0.5000 \\
\hline & & Multistoried buildings (9-10 floors) & 4 & 0.7500 \\
\hline & & Skyscrapers (> 10 floors) & 5 & 1.0000 \\
\hline \multirow{7}{*}{ Building age } & \multirow{7}{*}{0.10} & $<5$ years & 1 & 0.0000 \\
\hline & & 10 years & 2 & 0.1667 \\
\hline & & 20 years & 3 & 0.3333 \\
\hline & & 25 years & 4 & 0.5000 \\
\hline & & 30 years & 5 & 0.6667 \\
\hline & & 35 years & 6 & 0.8333 \\
\hline & & $>35$ years & 7 & 1.0000 \\
\hline
\end{tabular}

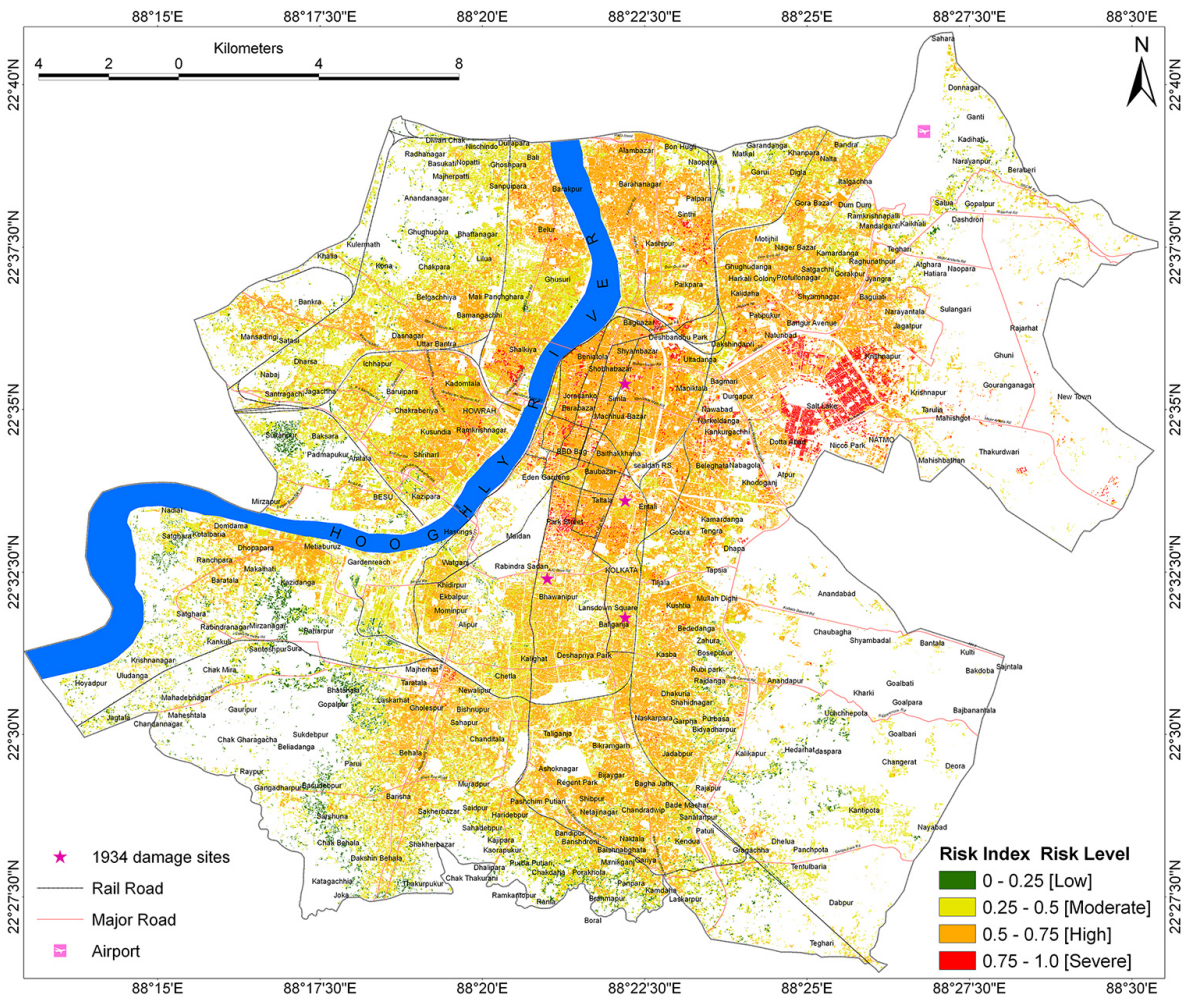

Figure 15. Probabilistic seismic structural risk map of Kolkata. Four broad divisions have been identified with risk index (SRI) defined as $0.75<\mathrm{SRI} \leq 1.0$, indicating "severe" risk condition in Salt Lake area; $0.50<\mathrm{SRI} \leq 0.75$, indicating "high" risk mostly in central Kolkata; $0.25<\mathrm{SRI} \leq 0.50$, depicting "moderate" risk in the most part of west Kolkata; and SRI $<0.25$, presenting a completely risk-free regime. The damage distribution due to the 1934 Bihar-Nepal earthquake of $M_{\mathrm{W}}=8.1$ (GSI, 1939) is identified in the highrisk zone (marked by an asterisk). The detailed structural attributions are presented in Table 8 . 
Table 8. Structural risk level with corresponding vulnerability exposures at selective locations in Kolkata.

\begin{tabular}{|c|c|c|c|c|c|c|c|c|c|c|}
\hline S1. & $\begin{array}{l}\text { Lat } \\
\left({ }^{\circ} \mathrm{N}\right)\end{array}$ & $\begin{array}{l}\text { Long } \\
\left({ }^{\circ} \mathrm{E}\right)\end{array}$ & LM & SRI & $P_{\mathrm{f}}$ & LPI & $I_{\mathrm{MM}}$ & $\mathrm{BH}$ & BA & $\mathrm{BT}$ \\
\hline 1 & 22.4940 & 88.311 & Behala & High & 1.4 & 3.3 & VII & Houses (1 floor) & 10 years & B: burnt bricks building \\
\hline 2 & 22.5125 & 88.388 & Rajdanga & Moderate & 1.5 & 12.1 & VII & Houses (1 floor) & 25 years & C1-i: concrete building \\
\hline 3 & 22.5971 & 88.367 & Shyambazar & High & 2.4 & 13.5 & VII & Buildings (2-4 floors) & 35 years & C1-i: concrete building \\
\hline 4 & 22.6346 & 88.424 & Dum Dum & High & 1.4 & 4.7 & VII & Buildings (2-4 floors) & 35 years & $\mathrm{C} 1-\mathrm{i}$ : concrete building \\
\hline 5 & 22.6468 & 88.344 & Bali & Moderate & 1.5 & 4.9 & VII & Buildings (2-4 floors) & $<5$ years & B: burnt bricks building \\
\hline 6 & 22.6190 & 88.305 & Kona & Moderate & 1.4 & 9.4 & VII & Buildings (2-4 floors) & 30 years & C1-i: concrete building \\
\hline 7 & 22.5037 & 88.252 & Maheshtala & Low & 1.4 & 3.6 & VII & Houses (1 floor) & 35 years & C1-i: concrete building \\
\hline 8 & 22.5269 & 88.327 & Alipur & High & 1.7 & 10.1 & VII & Tall buildings ( $5-8$ floors) & 10 years & C1-i: concrete building \\
\hline 9 & 22.5470 & 88.287 & Metiaburuz & High & 1.4 & 4.6 & VII & Tall buildings ( $5-8$ floors) & 25 years & C1-i: concrete building \\
\hline 10 & 22.4556 & 88.422 & Dabpur & Moderate & 1.7 & 27.5 & VII & Buildings (2-4 floors) & 25 years & B - Burnt bricks building \\
\hline 11 & 22.4938 & 88.379 & Jadavpur & High & 1.5 & 13.5 & VII & Tall buildings ( $5-8$ floors) & 35 years & $\mathrm{C} 1-\mathrm{i}$ : concrete building \\
\hline 12 & 22.5182 & 88.342 & Kalighat & Moderate & 1.4 & 4.2 & VII & Buildings (2-4 floors) & $>35$ years & A2: stone wall \\
\hline 13 & 22.4906 & 88.451 & Deara & Low & 1.4 & 21.2 & VII & Buildings (2-4 floors) & $<5$ years & B - Burnt bricks building \\
\hline 14 & 22.5092 & 88.379 & Dhakuria & High & 0.9 & 14.3 & VII & Tall buildings ( $5-8$ floors) & 10 years & C1-ii: newly built-up concrete B \\
\hline 15 & 22.4604 & 88.317 & Thakurpukur & Low & 1.5 & 3.8 & VII & Houses (1 floor) & 20 years & C1-i: concrete building \\
\hline 16 & 22.5817 & 88.328 & Howrah & High & 1.3 & 14.0 & VII & Houses (1 floor) & $>35$ years & C1-i: concrete building \\
\hline 17 & 22.5151 & 88.457 & Bakdoba & Moderate & 1.4 & 12.7 & VII & Houses (1 floor) & 30 years & B: burnt bricks building \\
\hline 18 & 22.6142 & 88.382 & Paikpara & High & 1.2 & 12.1 & VII & Buildings (2-4 floors) & $>35$ years & C1-i: concrete building \\
\hline 19 & 22.5527 & 88.354 & Park Street & Severe & 1.4 & 24.4 & VII & Multistoried buildings ( $9-10$ floors) & 20 years & C1-i: concrete building \\
\hline 20 & 22.5830 & 88.416 & Salt Lake & Severe & 1.2 & 28.1 & VII & Tall buildings ( $5-8$ floors) & 10 years & C1-ii: newly built-up concrete B \\
\hline 21 & 22.5854 & 88.480 & New Town & Moderate & 1.2 & 26.5 & VII & Buildings (2-4 floors) & $<5$ years & C1-ii: newly built-up concrete B \\
\hline 22 & 22.6030 & 88.468 & Rajarhat & Moderate & 0.9 & 34.3 & VII & Buildings (2-4 floors) & $<5$ years & C1-ii: newly built-up concrete B \\
\hline
\end{tabular}

LM is major land marks; SRI is structural risk index; $P_{\mathrm{f}}$ is predominant frequency; LPI is liquefaction potential index; $I_{\mathrm{MM}}$ is predicted MM Intensity; BH is building height; BA is building age (years); BT is building type as per BMTPC.

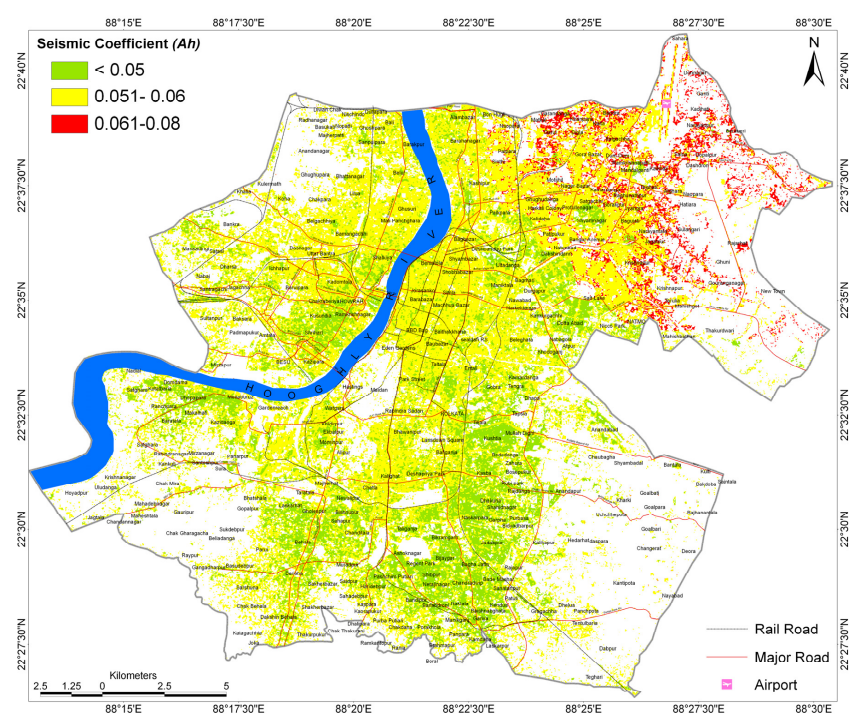

Figure 16. Spatial distribution of horizontal seismic coefficient $\left(A_{\mathrm{h}}\right)$ to be used for Kolkata for structures with $1.0 \mathrm{~s}$ predominant period.

specified the values of $I$ and $R$ for all kinds of buildings. The sample seismic coefficient $\left(A_{\mathrm{h}}\right)$ distribution to be used for Kolkata for all kinds of structures with the predominant period of $1.0 \mathrm{~s}$ is depicted in Fig. 16. Depending upon the value of seismic coefficient $\left(A_{\mathrm{h}}\right)$ the category of building has been defined by BIS (2002) as given in Table 9. From Fig. 16 it is evident that the city may be suitable for " $A$ " and " $B$ " struc- tures only. However "C" structures may also be built in the northeastern part of the city.

The probability of damage in each seismic risk zone is calculated in relation to the given ground motion parameters to evaluate the building performance for a particular seismic event. Based on the RVS technique and the capacity curves given in NIBS (2002), we have selected four model type buildings viz. RM2L, RM2M, URML and URMM in the city. In the present context, "RM2L", "RM2M" types represent "C" type structure while URML and URMM represent "B" type structure. We calculated the demand spectrum curve of spectral acceleration, the peak building response and the cumulative damage probabilities of all the four model building types. The demand spectrum curve of spectral acceleration is a function of spectral displacement, which for the periods 0.3 and $1.0 \mathrm{~s}$ has been used for the characterization of the ground motion demand. The spectral displacement has been determined by using the following equation (FEMA, 2001):

$S_{\mathrm{D}}=9.8 \cdot S_{\mathrm{A}} \cdot T^{2}$,

where $S_{\mathrm{A}}$ is the amplified spectral acceleration in $g$ (Nath et al., 2014), $T$ is the time period (seconds) and $S_{\mathrm{D}}$ is the spectral displacement (inches). The capacity curve represents the characteristics of a structure, which is a plot of lateral resistance of a building as a function of the characteristic lateral displacement (Molina et al., 2010). The capacity curve is characterized by three control points: design capacity, yield capacity and ultimate capacity. The capacity curve parameters for four model building types have been adopted from NIBS (2002). The peak building response is estimated from the interaction of the building capacity curve and the demand 
Table 9. Classification of building categories based on $A_{\mathrm{h}}$ (BIS, 2002).

\begin{tabular}{cll}
\hline Range of $A_{\mathrm{h}}$ & $\begin{array}{l}\text { Building } \\
\text { category }\end{array}$ & Description \\
\hline$<0.05$ & A & Building in field stone, rural structures, unburnt brick houses, clay houses \\
\hline $0.05-0.06$ & $\mathrm{~B}$ & $\begin{array}{l}\text { Ordinary brick buildings, buildings of large block and prefabricated type, } \\
\text { half timbered structures, buildings in natural hewn stone }\end{array}$ \\
\hline $0.06-0.08$ & $\mathrm{C}$ & Reinforced buildings, well-built wooden structures \\
\hline $0.08-0.12$ & $\mathrm{D}$ & Other type not covered in A, B, C \\
\hline$>0.12$ & E & \\
\hline
\end{tabular}

Table 10. Peak building response estimated for four significant model building types (FEMA, 2001).

\begin{tabular}{lllll}
\hline $\begin{array}{l}\text { Model } \\
\text { building }\end{array}$ & \multicolumn{3}{c}{$\begin{array}{c}\text { Peak building response } \\
\text { (inches) }\end{array}$} \\
\cline { 2 - 5 } & RM2L & RM2M & URML & URMM \\
\hline Type & $\begin{array}{l}\text { Reinforced masonry } \\
\text { bearing wall with } \\
\text { precast concrete } \\
\text { diaphragms, low rise } \\
(1-3 \text { stories })\end{array}$ & $\begin{array}{l}\text { Reinforced masonry } \\
\text { bearing wall with } \\
\text { precast concrete } \\
\text { diaphragms, medium } \\
\text { rise (4-7 stories) }\end{array}$ & $\begin{array}{l}\text { Unreinforced masonry } \\
\text { bearing wall, } \\
\text { low rise } \\
(1-2 \text { stories })\end{array}$ & $\begin{array}{l}\text { Unreinforced masonry } \\
\text { bearing wall, } \\
\text { medium rise } \\
\text { (3+ stories) }\end{array}$ \\
\hline$S_{\mathrm{D} \text { (inch) }}$ & 0.71 & 0.727 & 0.639 & 0.735 \\
\hline
\end{tabular}

curve at the specified building location. The peak building response at the point of interaction of the capacity curve and the demand curve is used with fragility curve for the estimation of damage state probability (Molina et al., 2010). Table 10 lists the calculated peak building response values for all the four model building types defined above. The cumulative damage probabilities have been calculated as (NIBS, 2002)

$p\left[d_{\mathrm{s}} \mid S_{\mathrm{d}}\right]=\Phi\left[\frac{1}{\beta_{d_{\mathrm{s}}}} \ln \left(\frac{S_{\mathrm{d}}}{\bar{S}_{\mathrm{d}, d_{\mathrm{s}}}}\right)\right]$,

where $p\left[d_{\mathrm{S}} \mid S_{\mathrm{d}}\right]$ is the probability of being in or exceeding a damage state, $d_{\mathrm{s}} ; S_{\mathrm{d}}$ is the given spectral displacement (inches); $\bar{S}_{d_{\mathrm{s}}}$ is the median value of $S_{\mathrm{d}}$ at which the building reaches the threshold of the damage state $d_{\mathrm{s}} ; \beta_{d_{\mathrm{s}}}$ is the lognormal standard deviation of spectral displacement of damage state, $d_{\mathrm{s}}$; and $\Phi$ is the standard normal cumulative distribution function. Table 11 enlists the cumulative damage probabilities of all four model building types in terms of none, slight, moderate, extensive and complete hazard. The discrete damage probability indicates that the UM2L and URML building typologies will suffer the lowest damage, while the RM2M and URMM building typologies will experience the most destruction during a strong earthquake in the city and its adjoining region.
Table 11. Estimated cumulative damage probabilities of four model building types defined in Table 10 .

\begin{tabular}{lccccc}
\hline $\begin{array}{l}\text { Model } \\
\text { type }\end{array}$ & \multicolumn{5}{c}{ Cumulative probabilities } \\
\cline { 2 - 6 } & None & Slight & Moderate & Extensive & Complete \\
\hline RM2L & 0.1402 & 0.3103 & 0.4123 & 0.0942 & 0.0429 \\
RM2M & 0.0547 & 0.2668 & 0.4472 & 0.1647 & 0.0666 \\
URML & 0.1831 & 0.3339 & 0.3334 & 0.1092 & 0.0403 \\
URMM & 0.0264 & 0.2125 & 0.3827 & 0.2675 & 0.1108 \\
\hline
\end{tabular}

\section{Conclusions}

Seismic vulnerability and risk have emerged as important issues in high-risk urban centers across the globe and are considered integral parts of earthquake-inflicted disaster mitigation and management. The seismic risk framework adopted here is a multidimensional protocol based on the integrated seismic hazard and vulnerability exposures, viz. population density, land use/land cover, building typology, building height and building age, judiciously integrated in the GIS to identify those structural and socioeconomic conditions which are responsible for turning an earthquake disaster into a catastrophe. Thus the knowledge of the risk in the city based on the existing built-up urban environment will immensely benefit the disaster mitigation and management endeavors put in place for the city of Kolkata. 
Acknowledgements. This work has been supported by the Ministry of Earth Sciences, Government of India vide sanction order no. MOES/P.O.(seismo)/1(60)/2009. The support received from the Department of Disaster Management and Civil Defence, government of West Bengal, for the smooth execution of the project is thankfully acknowledged. We greatly appreciate the tremendous support received from the editorial board of NHESS especially Bruce D. Malamud, the Chief Executive Editor and David Keefer, the erstwhile Handling Editor for this manuscript during its marathon review and discussion process. The three anonymous reviewers critically examined the manuscript and its subsequent revisions suggesting several valuable changes that greatly helped in bringing up the manuscript to its present level with enhanced scientific value addition and greater exposition.

Edited by: B. D. Malamud

Reviewed by: three anonymous referees

\section{References}

Aghataher, R., Delavar, M. R., Nami, M. H., and Samnay, N.: A Fuzzy-AHP Decision Support System for Evaluation of Cities Vulnerability against Earthquakes, World Applied Sciences, IDOSI Publications, 3, 66-72, 2008.

Alam, M., Alam, M. M., Curray, J. R., Chowdhury, M. L. R., and Gani, M. R.: An overview of sedimentary geology of the Bengal Basin in relation to the regional framework and basin-fill history, Sediment. Geol., 155, 179-208, 2003.

Anbazhagan, P., Thingbaijam, K. K. S., Nath, S. K., Narendara Kumar J. N., and Sitharam, T. G.: Multi-criteria seismic hazard evaluation for Bangalore city, India, J. Asian Earth Sci., 38, 186-198, 2010.

Bilham, R., Gaur, V. K., and Molnar, P.: Himalayan seismic hazard, Science, 293, 1442-1444, 2001.

BIS: IS 1893-2002 (Part 1): Indian Standard Criteria for Earthquake Resistant Design of Structures, Part 1 - General Provisions and Buildings, Bureau of Indian Standards, New Delhi, 2002.

Bishop, Y. M. M., Fienberg, S. E., and Holland, P. W.: Discrete Multivariate Analysis Theory and Practice, MIT Press, Carnbridge, Massachusetts, 557 pp., 1975.

BMTPC: Vulnerability Atlas of India: Earthquake, Windstorm and Flood Hazard Maps and Damaged Risk to Housing, Ministry of Housing and Urban poverty Alleviation, Government of India, First Revision, 1997.

Census India: 2011 Census of India, available at: http://censusindia. gov.in, last access: May 2012, 2011.

Congalton, R. G.: Review of assessing the accuracy of classifications of remotely sensed data, Remote Sens. Environ., 37, 35-46, 1991

Congalton, R. G. and Green, K.: Assessing the Accuracy of Remotely Sensed Data: Principles and Practices, CRC Press, Inc, Boca Raton, Florida, 137 pp., 1999.

Congalton, R. G. and Mead, R. A.: A quantitative method to test for consistency and correctness of photo interpretation, Photogramm. Eng. Rem. S., 49, 69-74, 1983.

Cutter, S. L., Boruff, B. J., and Shirley, W. L.: Social vulnerability to environmental hazards, Soc. Sci. Quart., 84, 242-261, 2003.
Das, D. and Chattopadhyay, B. C.: Methods for Seismic Microzonation with SWV: A Comparative Study, Indian Geotechnical Conference, GEOtrendz, IGS Mumbai Chapter \& IIT Bombay, 16$18,2010$.

Dasgupta, S., Sural, B., Harendranath, L., Mazumadar, K., Sanyal, S., Roy, A., Das, L. K., Misra, P. S., and Gupta, H.: Seismotectonic Atlas of India and its Environs, Geological Survey of India, Calcutta, India, 2000.

Dunbar, P. K., Bilham, R. G., and Laituri, M. J.: Earthquake loss estimation for India based onmacroeconomic indicators, in: Risk Science and Sustainability, edited by: Beer, T. and Ismail-Zadeh, A., Kluwer Academic Publishers, Dordrecht, 163-180, 2003.

FEMA: HAZUS99 Estimated Annualized Earthquake Loss for the United States, Report FEMA 366, Federal Emergency Management Agency, Washington, DC, USA, 2001.

Geneletti, D. and Gortea, H. G. B.: A method for object-oriented land cover classification combining Landsat TM data and aerial photographs, Int. J. Remote Sens., 24, 1237-1286, 2003.

GSI: The Bihar-Nepal Earthquake of 1934, Memoirs of the Geological Survey of India, 73, 391 pp., 1939.

HAZUS: National Institute of Building Science - earthquake loss estimation methodology, technical manual, Report prepared for the Federal Emergency Management Agency, Washington, D.C., available at: www.fema.gov/plan/prevent/hazus, last access: July 2013, 1999.

Idriss, I. M. and Boulanger, R. W.: Semi-empirical procedures for evaluating liquefaction potential during earthquakes, Soil Dyn. Earthq. Eng., 26, 115-130, 2006.

Ishita, R. P. and Khandaker, S.: Application of analytical hierarchical process and GIS in earthquake vulnerability assessment: case study of Ward 37 and 69 in Dhaka City, Journal of Bangladesh Institute of Planners, 3, 103-112, 2010.

Iwasaki, T., Tokida, K., Tatsuoka, F., Watanabe, S., Yasuda, S., and Sato, H.: Microzonation for soil liquefaction potential using simplified methods, in: Proceedings of the 3rd International Conference on Microzonation, Seattle, 3, 1319-1330, 1982.

Jensen, J. R.: Introductory Digital Image Processing: a Remote Sensing Perspective, 2nd Edn., Prentice Hall Inc., Upper Saddle River, New Jersey, USA, 1996.

Kramer, S. L.: Geotechnical Earthquake Engineering, Prentice Hall, Upper Saddle River, NJ, 653 pp., 1996.

Kundu, A. K. and Aag, P.: Atlas of the City of Calcutta and its Environs, National Atlas and Thematic Mapping Organization, Ministry of Science and Technology, Government of India, 1996.

Landis, J. R. and Koch, G. G.: The measurement of observer agreement for categorical data, Biometrics, 33, 159-174, 1977.

Lermo, J. and Chávez-García, F. J.: Site effect evaluation using spectral ratios with only one station, B. Seismol. Soc. Am., 83, 1574-1594, 1993.

Lu, D. and Weng, Q.: Urban classification using full spectral information of Landsat ETM Imagery in Marion County, Indiana, Photogramm. Eng. Rem. S., 71, 1275-1284, 2005.

McGuire, R. K.: Seismic Hazard and Risk Analysis, EERI Publication, No MN0-10, 2004.

Middlemiss, C. S.: Two Calcutta Earthquakes of 1906, Records of the Geological Survey of India, 36, 214-232, 1908.

Molina, S., Lang, D. H., and Lindholm, C. D.: SELENA-an opensource tool for seismic risk and loss assessment using a logic tree computation procedure, Comput. Geosci., 36, 257-269, 2010. 
Nakamura, Y.: A method for dynamic characteristics estimations of subsurface using microtremors on the ground surface, Quartely Report of Railway Technical Research Institute (RTRI), 30, 2533, 1989.

Nandy, D. R.: Need for seismic microzonation of Kolkata megacity, Proceedings of workshop on microzonation, Indian Institute of science, Bangalore, India, 2007.

Nath, S. K.: Seismic hazard mapping in sikkim himalaya through GIS integration of site effects and strong ground motion attributes, Nat. Hazards, 31, 319-342, 2004.

Nath, S. K. and Thingbaijam, K. K. S.: Seismic hazard assessmenta holistic microzonation approach, Nat. Hazards Earth Syst. Sci., 9, 1445-1459, doi:10.5194/nhess-9-1445-2009, 2009.

Nath, S. K., Thingbaijam, K. K. S., Vyas, J. C., Sengupta, P., and Dev, S. M. S. P.: Macroseismic-driven site effects in the southern territory of West Bengal, India, Seismol. Res. Lett., 81, 480-487, 2010.

Nath, S. K., Adhikari, M. D., Maiti, S. K., Devaraj, N., Srivastava, N., and Mohapatra, L. D.: Earthquake scenario in West Bengal with emphasis on seismic hazard microzonation of the city of Kolkata, India, Nat. Hazards Earth Syst. Sci., 14, 2549-2575, doi:10.5194/nhess-14-2549-2014, 2014.

NIBS: HAZUS99 - earthquake loss estimation methodology, technical manual, in: Technical Manual, edited by: FEMA, Federal Emergency Management Agency (FEMA), National Institute of Building Sciences (NIBS), Washington DC, 325 pp., 2002.

O'Malley, J.: US Geological Survey ArcMap Sediment Classification Tool: Installation and User Guide, USGS, Open-File Report 2007-1186, 2007.

Panahi, M., Rezaie, F., and Meshkani, S. A.: Seismic vulnerability assessment of school buildings in Tehran city based on AHP and GIS, Nat. Hazards Earth Syst. Sci., 14, 969-979, doi:10.5194/nhess-14-969-2014, 2014.

Qunlin, J., Bai, P., and Duan, Q.: Risk assessment on Beijing urban infrastructure vulnerability, in: Proceedings of the 2nd International Conference on Systems Engineering and Modeling (ICSEM-13), Atlantis Press, Paris, France, 2013.

RADIUS: Risk Assessment Tools for Diagnosis of Urban Areas against Seismic Disasters, available at: www.eird.org/eng/ revista/No2_2001/pagina21.htm, last access: June 2012, 2000.

Reveshty, M. A. and Gharakhlou, M.: Modeling of Urban Building Vulnerability in Earthquake against using Analytical Hierarchy Process (AHP) and GIS, a Case Study on Zanjan City, Northwest of Iran, available at: http://www.mapasia.org/2009/proceeding/ urban_regional/ma09Mohsen.pdf, last access: September 2010, 2009.
Roy, P. K., Banerjee, G., Mazumdar, A., Kar, A., Majumder, A., and Roy, M. B.: A study to ascertain the optimum yield from groundwater source in the eastern part of Kolkata municipal corporation area in West Bengal, India, European Journal of Sustainable Development, 1, 97-112, 2012.

Rumsey, D.: David Rumsey Historical Map Collection of 1800 and 1958, available at: http://www.davidrumsey.com, last access: May 2013.

Saaty, T. L.: The Analytic Hierarchy Process, McGraw-Hill International, New York, NY, USA, 1980.

Sarris, A., Loupasakis, C., Soupios, P., Trigkas, V., and Vallianatos, F.: Earthquake vulnerability and seismic risk assessment of urban areas in high seismic regions: application to Chania City, Crete Island, Greece, Nat. Hazards, 54, 395-412, 2010.

Sinha, R. and Adarsh, N.: A postulated earthquake damage scenario for Mumbai, ISET Journal of Earthquake Technology, 36, 169$183,1999$.

Small, C.: Multi-temporal analysis of urban reflectance, Remote Sens. Environ., 81, 427-442, 2002.

Story, M. and Congalton, G. R.: Accuracy assessment: a user's perspective, Photogramm. Eng. Rem. S., 52, 397-399, 1986.

Wyss, M.: Human losses expected in Himalayan earthquakes, Nat. Hazards, 34, 305-314, 2005.

Youd, T. L., Idriss, I. M., Andrus, R. D., Arango, I., Castro, G., Christian, J. T., Dobry, R., Finn, W. D. L., Harder Jr., L. F., Hynes, M. E., Ishihara, K., Koester, J. P., Liao, S. S. C., Marcuson-III, W. F., Martin, G. R., Mitchell, J. K., Moriwaki, Y., Power, M. S., Robertson, P. K., Seed, R. B., and Stokoe II, K. H.: Liquefaction resistance of soils: summary report from the 1996 NCEER and 1998 NCEER/NSF workshops on evaluation of liquefaction resistance of soils, J. Geotech. Geoenviron., 127, 817-833, 2001.

Zha, Y., Gao, J., and Ni, S.: Use of normalized difference built-up index in automatically mapping urban areas from TM imagery, Int. J. Remote Sens., 24, 583-594, 2003.

Zhang, Q., Wang, J., Peng, X., Gong, P., and Shi, P.: Urban built-up land change detection with road density and spectral information from multi-temporal Landsat TM data, Int. J. Remote Sens., 23, 3057-3078, 2002. 